\title{
A novel compound that disrupts mitotic spindle poles in human cells
}

$9 \wedge$ Equal contribution Canada

\section{ABSTRACT} its anti-cancer potential.

Dilan Jaunky $^{1}$, Mathieu Husser ${ }^{1 \wedge}$, Kevin Larocque ${ }^{1 \wedge}$, Peter Liu ${ }^{2}$, Sajinth Thampipillai ${ }^{1}$, Pat Forgione $^{2}$, Alisa Piekny ${ }^{1 *}$

1. Department of Biology, Concordia University, Montreal, QC, Canada

2. Department of Chemistry and Biochemistry, Concordia University, Montreal, QC,

\section{*Correspondence: Alisa Piekny, PhD, Associate Professor; alisa.piekny@,concordia.ca}

Keywords: microtubules, mitosis, centrosome, colchicine, spindle

We characterize the mechanism of action of a new microtubule-targeting compound in cells. Microtubule-targeting drugs are used as successful anti-cancer therapies. We synthesized a family of compounds that share a common scaffold and have several functional groups amenable to modifications. We found that one of the active derivatives, $\mathrm{C} 75$, reduces cell viability and prevents microtubule polymerization in vitro. In this study, we explore the phenotypes caused by C75 in cells. It causes mitotic arrest and spindle phenotypes in several cancer cell lines in the nanomolar range. $\mathrm{C} 75$ can bind to the Colchicine-pocket on tubulin in vitro, but causes different effects on microtubules in cells. While Colchicine causes a decrease in microtubules and spindle pole collapse without re-growth, similar concentrations of C75 cause a rapid loss of microtubules and spindle pole fragmentation followed by microtubule re-growth to form multipolar spindles. In addition, C75 and Colchicine synergize for reduced viability and spindle phenotypes. Importantly, the phenotypes caused by C75 are similar to those caused by the depletion of ch-TOG, a microtubule polymerase, and tubulin and ch-TOG are displaced and oscillate in C75-treated cells. This suggests that $\mathrm{C} 75$ causes microtubule depolymerization in cells either directly or indirectly via inhibiting ch-TOG. This unique effect of $\mathrm{C} 75$ on microtubules warrants further exploration of 


\section{Introduction}

Dynamic microtubules are required for mitotic spindle assembly and function, and drugs that suppress these dynamics are used to treat cancer (Cirillo et al. 2017; Kozielski 2015; Musacchio 2015). At the G2/M transition, there is an increase in microtubule growth from the maturing centrosomes. Dimers of $\alpha$-tubulin and $\beta$-tubulin form 13 protofilaments that roll into a tubule, which are templated by the $\gamma$-tubulin ring complex ( $\gamma$-TURC; Oakley et al. 2015; Martin and Akhmanova 2018). GTP-binding and hydrolysis influences microtubule structure and can promote growth or catastrophe (Wordeman 2019; Martin and Akhmanova 2018; Brouhard and Rice 2018). Straightening of the protofilament plus-ends are crucial for microtubule stability and growth. During catastrophe or under drug-induced conditions that destabilize the plus-end, the protofilaments will adopt a curved state and bend away from the lumen (Gigant et al. 2005; Akhmanova and Steinmetz 2015; Goodson and Jonasson 2018). The growth and shrinkage of microtubules is required to form stable kinetochore attachments with sister chromatids, and many microtubule-associated proteins (MAPs) influence microtubule dynamics by stabilizing the minus and/or plus ends (Goodson and Jonasson 2018). MAPs include microtubule motors that bundle and organize microtubules to form bipolar spindles, as well as enzymes such as ch-TOG and MCAK that control microtubule polymerization and depolymerization, respectively (Widlund et al. 2011; Zhang et al. Walczak 2008; Gergely et al. 2003; Holmfeldt et al. 2004; Barr and Gergely 2008; Brouhard et al. 2008; Barr and Bakal 2015; Brouhard and Rice 2018). When stable kinetochore attachments are achieved by both sister chromatids, this generates tension that is sensed by the spindle assembly checkpoint for mitotic exit and the segregation of sister chromatids

52 (Musacchio 2015). Microtubule-targeting drugs that suppress microtubule dynamics and prevent

53 the formation of stable kinetochore attachments can lead to cell cycle arrest or catastrophe, and 54 cell death.

Several different microtubule-targeting drugs are currently being used to treat cancers. One

56 of the hallmarks of cancer is uncontrolled cell proliferation, and this property can make cancer

57 cells more responsive to compounds that arrest different stages of the cell cycle compared to 58 healthy cells (Hanahan and Weinberg 2011; Dominguez-Brauer et al. 2015). Taxol ${ }^{\mathrm{TM}}$ is a 59 microtubule-targeting compound that causes mitotic arrest or catastrophe and is used to treat a plethora of cancers (Weaver 2014). Taxol binds to microtubules and stabilizes the lattice to prevent

61 depolymerization (Kumar 1981; Parness and Horwitz 1981). This prevents the formation of stable 
62 kinetochore attachments, and failed segregation of sister chromatids (Zasadil et al. 2014).

63 Depending on the other genetic changes in the cell, this can trigger the spindle assembly

64 checkpoint, or cause mitotic catastrophe (Zasadil et al. 2014). Although Taxol offers some success

65 in the clinic, it can cause severe side-effects and some patients develop resistance (Kavallaris

66 2010). Thus, there is a need to develop alternative drugs that can reduce the concentrations of

67 Taxol needed for treatment to reduce side-effects and resistance.

Cancer cells often accumulate mutations that alter the expression and/or function of MAPs, motor proteins and microtubule-regulating enzymes, which causes them to have increased sensitivity to microtubule-targeting drugs (Cirillo et al. 2017; Kozielski 2015; Musacchio 2015; Brito and Rieder 2010). Coupling the depletion of MCAK and treatment with low concentrations of Taxol in cancer cells causes a dramatic increase in the proportion of cells in mitosis with multipolar spindles, and increased apoptosis (Hedrick et al., 2008). In colorectal cancer cells, Aurora A kinase, which regulates centrosome maturation and plus-end dynamics for kinetochore attachments, and ch-TOG (CKAP5), a microtubule polymerase, are over-expressed (Holmfeldt et al. 2004; Fielding et al. 2011; Barr and Bakal 2015; Al-Bassam and Chang 2011; Byrnes and Slep 2017; Yu et al. 2016; Hood et al. 2013). Their overexpression correlates with increased rates of microtubule assembly and chromosomal instability (CIN) due to excess lagging chromosomes (Ertych et al., 2014, Byrnes and Slep 2017). These properties could make mitotic spindles sensitive to further disruption by microtubule-targeting drugs compared to healthy cells. However, if CIN cells have lost tumor suppressors or checkpoint regulators, they could lose their responsiveness to these drugs and retain tumor growth properties (Ertych et al., 2014).

Another class of microtubule targeting compounds prevents polymerization or causes depolymerization of microtubules depending on their concentration and accessibility. These altered dynamics cause mitotic arrest or catastrophe similar to Taxol and have been used or considered for use as anti-cancer therapies. Colchicine was discovered by Gary Borisy (1967) and led to the biochemical purification of tubulin (Borisy and Taylor 1967). Colchicine binds to a deep pocket on $\beta$-tubulin and prevents growth or causes catastrophe at the plus-end (Fitzgerald 1976;

91 Vinblastine also prevents microtubule polymerization or causes microtubule depolymerization,

92 and is being used as an anti-cancer drug (Martino et al. 2018; Gigant et al. 2005). It binds to the 
interface of the heterodimer and introduces a molecular wedge causing the protofilaments to adopt a curled conformation that effectively destabilizes the microtubule (Martino et al. 2018; Gigant et al. 2005; Jordan and Kamath 2007). Vinblastine causes lower side-effects compared to Colchicine, and this higher tolerance could explain its success as an anti-cancer drug compared to Colchicine. In addition to having distinct binding sites, they could have different properties in vitro and in vivo, including accessibility to the minus vs. plus ends that alters their affinity and how they affect the microtubule polymer. In vitro, Vinblastine favours depolymerization at the minus ends of polymerized microtubules and suppression of dynamics at the plus ends (Panda et al., 1996). In HeLa cells, low concentrations (e.g. $2 \mathrm{nM}$ ) of Vinblastine did not cause obvious changes in the microtubule polymer mass, but blocked mitosis by decreasing kinetochore attachments, as well as the dissociation of mother and daughter centrioles and loss of centriole ultrastructure (Jordan et al., 1992; Wendell et al., 1993).

We recently synthesized a novel family of compounds that target microtubules (manuscript submitted). Our approach was to strategically design and synthesize a family of compounds with properties ideal for in vivo use and screen derivatives for their ability to arrest cancer cell proliferation. The compounds share a common core thienoisoquinoline scaffold amenable to modifications via structure-activity-relationship (SAR) studies (Chen et al. 2014). We identified several derivatives that cause mitotic arrest with an $\mathrm{IC}_{50}$ for viability in the nanomolar range. Importantly, some derivatives have no or little effect on cells (e.g. C87, $\mathrm{IC}_{50}>10 \mathrm{uM}$ ) while others have high efficacy (e.g. $\mathrm{C} 75, \mathrm{IC}_{50}$ between $0.1-0.4 \mathrm{uM}$ depending on the cell line). We also found that $\mathrm{C} 75$ prevents microtubule polymerization in vitro, suggesting that it can bind to tubulin. mechanism of action in cells. We found that despite being able to bind to the same pocket as Colchicine in vitro, C75 has different effects on microtubule polymers and mitotic spindle organization. C75 causes cancer cells to arrest in mitosis with aberrant spindles, misaligned chromosomes and spindle pole fragmentation. Adding C75 and Colchicine together showed synergistic effects at several concentrations in HeLa and HCT 116 cells, suggesting differences in

121 but unlike Colchicine, C75 also causes spindle pole fragmentation and microtubule re-growth to 122 form multipolar spindles. The spindle phenotypes that arise due to $\mathrm{C} 75$ are similar to those caused 
124 Interestingly, spindle pole components are displaced and oscillate upon C75-treatment, suggesting 125 that it has accessibility to the minus ends. Therefore, C75 is a novel microtubule-targeting drug 126 with effects on microtubule polymers that appear to be distinct from those caused by Colchicine. 127 While it promotes depolymerization, the re-growth and formation of multipolar spindles make it 128 an interesting compound to explore further for in vivo use to disrupt tumor growth. 


\section{Material and Methods}

\section{Cell culture and drug treatments}

HeLa and HFF-1 cells were grown in DMEM (Wisent), while A549 cells were grown in F12K media (Wisent) and HCT 116 (p53-/-) cells were grown in McCoy's media (Wisent) in humidified incubators at $37^{\circ} \mathrm{C}$ with $5 \% \mathrm{CO}_{2}$. All media were supplemented with $10 \%$ fetal bovine serum (FBS; Thermo Scientific), 2 mM L-glutamine (Wisent), $100 \mathrm{U}$ penicillin (Wisent), and 0.1 $\mathrm{mg} / \mathrm{mL}$ streptomycin (Wisent).

C87 and $\mathrm{C} 75$ were stored at $-20^{\circ} \mathrm{C}$ as $1 \mathrm{mM}$ stocks in dimethyl sulfoxide (DMSO). Working stocks of $100 \mu \mathrm{M} \mathrm{C75}$ or C87 were made in DMSO: $\mathrm{H}_{2} \mathrm{O}$ (9:1). Colchicine (Sigma) was dissolved in ethanol as a $1 \mathrm{M}$ stock and diluted to $10 \mu \mathrm{M}$ before use. Final concentrations of DMSO or ethanol were kept below $0.5 \%$.

\section{Microtubule assays}

Microtubule polymerization assays were performed using $1.5 \mathrm{mg} / \mathrm{mL}$ purified tubulin (Cytoskeleton, Inc) that was taken from a $10 \mathrm{mg} / \mathrm{mL}$ flash frozen stock, thawed on ice and diluted in G-PEM buffer (80 mM PIPES pH 6.9, $2 \mathrm{mM} \mathrm{MgCl}_{2}, 0.5 \mathrm{mM}$ EGTA and $1 \mathrm{mM}$ GTP with $20 \%$ glycerol) with $10 \%$ DMSO (control) or $250 \mathrm{nM} \mathrm{C75}$. Assays were performed in a preheated $50 \mathrm{uL}$ sub micro Z15 black Q/Spectrosil cuvette in a Varian Cary 1 spectrophotometer. Reagents were added to the cuvette and blanked immediately before recording absorbance at $340 \mathrm{~nm}$ in 0.1 second intervals for 45 minutes.

We determined the effect of $\mathrm{C} 75$ on polymerized microtubules by sedimentation. Lyophilized microtubules (Cytoskeleton, Inc) were reconstituted to $5 \mathrm{mg} / \mathrm{mL}$ in PM buffer (15 $\mathrm{mM}$ PIPES $\mathrm{pH} 7.0,1 \mathrm{mM} \mathrm{MgCl}$, and $2 \mathrm{mM}$ Taxol) and aliquots were snap frozen in liquid nitrogen and stored at $-80^{\circ} \mathrm{C}$. Aliquots were thawed on ice in a circulating water bath, then diluted to $2 \mathrm{mg} / \mathrm{mL}$ in PM buffer at room temperature. Microtubules $(1 \mu \mathrm{M})$ were incubated with $5 \mu \mathrm{M}$ of C75, Taxol, or Colchicine in a general tubulin buffer $(80 \mathrm{mM}$ PIPES pH 6.9, $2 \mathrm{mM} \mathrm{MgCl}, 0.5$ mM EGTA) for 15 minutes. Then the samples were centrifuged at $16,000 \mathrm{xg}$ for 1 hour. The supernatant and pellets were resuspended in sample buffer without SDS or DTT and run on by native PAGE on an $8 \%$ polyacrylamide gel.

Colchicine-competition assays were performed with $2 \mu \mathrm{M}$ purified tubulin (Cytoskeleton, Inc) taken from a $10 \mathrm{mg} / \mathrm{mL}$ stock prepared in tubulin buffer as above, and the binding assays were 
performed with $1 \mu \mathrm{M}$ Colchicine or $1 \mu \mathrm{M}$ Colchicine with $500 \mathrm{nM}$ C75 in $25 \mathrm{mM}$ PIPES buffer, pH 6.8 in a $600 \mu \mathrm{L}$ Q fluorometer cell, $Z=20$ (Varian) using a fluorescence spectrophotometer

162 Cary Eclipse (Varian) at $25{ }^{\circ} \mathrm{C}$ for 3 hours. Reaction mixtures were excited at $350 \mathrm{~nm}$ and the emission was measured from 380 to $500 \mathrm{~nm}$ (Bhattacharyya and Wolff, 1974). Emission values were collected at 30-minute intervals and normalized to the spectra recorded at time zero. All values were exported as excel files and graphs were generated in Prism V8.1.0 Graphpad.

Viability assays

Assays were performed to determine the viability of cells after treatment with $\mathrm{C} 75$ and/or Colchicine. The concentration of Colchicine or C75 used in the combination experiments was the highest concentration that caused little to no toxicity based on dose-response curves. HFF-1, HeLa, A549 and HCT 116 cells were plated with 4,000 cells/well in 96-well dishes and left overnight to adhere. Drug dilutions were prepared and added to the cells using an acoustic liquid handler

173 (LabCyte ECHO 550). After 3 population doubling times, cells were assessed for viability using 174 the WST-8 cell proliferation assay kit (Cayman Chemicals). Absorbance readings at $450 \mathrm{~nm}$ were 175 collected using the TECAN 200 PRO plate reader. Values for each replicate were adjusted to the controls and plotted using GraphPad Prism 7 to generate graphs and $\mathrm{IC}_{50}$ values. All assays were performed in triplicate for each treatment. For the combination assays, C75 or Colchicine were repeated alongside the combination treatments to ensure accurate comparison.

Flow cytometry

Flow cytometry was used to measure changes in the proportion of cells in different stages of the cell cycle after C75-treatment. HeLa, HCT 116 and A549 cells were grown to 80\% confluency and treated with a range of C75 concentrations for 8 hours. Cells were harvested in

184 falcon tubes, then fixed with 70\% cold ethanol and washed with cold phosphate buffered saline 185 (PBS; Wisent). Cells were permeabilized and stained for 15 minutes at $37^{\circ} \mathrm{C}$ with a solution containing $500 \mu \mathrm{g} / \mathrm{mL}$ PI (Sigma) in PBS with 0.1\% (v/v) Triton X-100 and DNAse-free RNAse

187 A (Sigma). Cells were protected from light and measured for PI intensity using the BD 188 LSRFortessa flow cytometer with excitation at $561 \mathrm{~nm}$ and detection at $600 \mathrm{~nm}$ (LP) using the D-BP filter. Each treatment was done in triplicate with 20,000 cells analyzed per sample. Data was exported and plotted using GraphPad Prism 7 to make bar graphs. 


\section{Immunofluorescence staining}

Immunofluorescence was performed to monitor mitotic spindle phenotypes. Cultured cells were plated on coverslips at a confluency of $40-50 \%$ and left overnight to adhere. Cells were fixed using freshly prepared ice-cold $10 \% \mathrm{w} / \mathrm{v}$ cold trichloroacetic acid (TCA) for 14 minutes at $4{ }^{\circ} \mathrm{C}$. Cells were washed with PBST $(0.3 \%$ Triton $\mathrm{X}-100)$ and kept at $4{ }^{\circ} \mathrm{C}$ prior to staining. After blocking, fixed cells were immunostained for microtubules using 1:400 mouse anti- $\alpha$-tubulin antibodies (DM1A; Sigma) or centrosomes using 1:400 mouse anti- $\gamma$-tubulin antibodies (Santa Cruz Biotechnology) or mouse anti-Centrin 2 (clone 20H5; Sigma), and centromeres using 1:500 human anti-centromere antibodies (ACA; Sigma) for 2 hours at room temperature. After washing, anti-mouse Alexa 488 and anti-human Alexa 647 (Invitrogen) secondary antibodies were used at a 1:500 dilutions for 2 hours at room temperature. After washing, 4',6-Diamidino-2'-phenylindole dihydrochloride (DAPI; Sigma) was added for 5 minutes. Cells were then washed with PBST, followed by a wash with $0.1 \mathrm{M}$ Tris $\mathrm{pH} 9$, then a drop of mounting media ( $0.5 \%$ propyl gallate in $50 \%$ glycerol) was added to the coverslip, which was mounted onto a slide and sealed.

\section{Microscopy}

Fixed slides were imaged using the Nikon-TIE inverted epifluorescence microscope with Lambda XL LED light sources, using the 60x/1.4 oil objective, a Piezo Z stage (ASI), a

210 Photometrics Evolve 512 EMCCD camera and Elements acquisition software (Nikon). Exposures

211 were determined by control cells, and the same settings were used in the treatment conditions.

212 Images were acquired as $1 \mu \mathrm{m}$ Z-stacks and exported as TIFFs, which were opened as maximum

213 intensity Z-stack projections in Image J (NIH). Merged colour images were converted into 8-bit 214 images and imported into Illustrator (Adobe) to make figures.

215 For live imaging, HeLa cells were plated to 50-60\% confluency on $25 \mathrm{~mm}$ round 216 coverslips (No. 1.5; Neuvitro). Cells were treated with 75 nM Hoescht 33342 and 200 nM SiR217 tubulin (Cytoskeleton Inc.) for 90 minutes prior to imaging. Depending on the experiment, 218 HeLa cells were transfected with a plasmid that expresses RNAi-resistant ch-TOG:GFP plus a 219 hairpin RNA (sh ch-TOG) to knockdown endogenous protein and minimize overexpression 220 (Addgene ID\# 69113). HeLa cells stably expressing GFP:tubulin were previously generated 221 (van Oostende Triplet et al., 2014). Coverslips were transferred to a $35 \mathrm{~mm}$ chamlide magnetic 
222 chamber (Quorum) and kept at $37^{\circ} \mathrm{C}$ with $5 \% \quad \mathrm{CO}_{2}$ using an INU-TiZ-F1 chamber

223 (MadCityLabs). Images were acquired using the 60x/1.4 oil objective on the Nikon Livescan

224 sweptfield confocal microscope with an Andor iXon X3 EMCCD camera and Elements

225 acquisition software (Nikon). The $405 \mathrm{~nm}, 480 \mathrm{~nm}$ and $640 \mathrm{~nm}$ lasers were used to image

226 Hoescht, GFP and sir-Tubulin, respectively, with a quad filter and exposures set to controls. Z-

227 stacks of $1 \mu \mathrm{m}$ were collected using a NI-DAQ piezo Z stage (National Instruments). Images

228 were used to make figures as described above.

229 To analyze the recovery of microtubules after cold-treatment in cells, HeLa cells were 230 plated onto coverslips and transferred to a $35 \mathrm{~mm}$ chamlide magnetic chamber (Quorum), which

231 was placed in an ice-cold water bath to cause spindle collapse. After 30 minutes, the cells were

232 transferred to $37^{\circ} \mathrm{C}$ with $5 \% \mathrm{CO}_{2}$ using an INU-TiZ-F1 chamber (MadCityLabs) and $\mathrm{C} 75$ or

233 Colchicine was added after acquisition of the first timepoint. Images were acquired using the

$23460 \mathrm{x} / 1.4$ oil objective on the Nikon Livescan sweptfield confocal microscope with an Andor

235 iXon X3 EMCCD camera and Elements acquisition software (Nikon). The $405 \mathrm{~nm}$ and $480 \mathrm{~nm}$

236 lasers were used to image Hoescht 33342, GFP:tubulin respectively, with a quad filter and

237 exposures set to controls. Z-stacks of $1 \mu \mathrm{m}$ were collected using a NI-DAQ piezo Z stage

238 (National Instruments). Images were used to make figures as described above.

Analysis

241 For the analysis of phenotypes in the Figures 2, 3, S3, 4 and 6, either whole fields of view

242 (Figure 2A) or z-stack projections of individual cells were used (Figures 2B, C, D, 3B, C, S3B,

$2434 \mathrm{~B}, 6 \mathrm{~A}, \mathrm{~B})$. To calculate the proportion of mitotic cells based on cell rounding (Figure 2A) we

244 counted the following number of HeLa cells on average: $0 \mathrm{nM} \mathrm{n}=568,100 \mathrm{nM} \mathrm{n}=847,200 \mathrm{nM}$

$245 \mathrm{n}=266,300 \mathrm{nM} \mathrm{n}=105,400 \mathrm{nM} \mathrm{n=96,} 500 \mathrm{nM} \mathrm{n=75),} \mathrm{A549} \mathrm{cells:} 0 \mathrm{nM} \mathrm{n=461,} 100 \mathrm{nM} \mathrm{n}=519$,

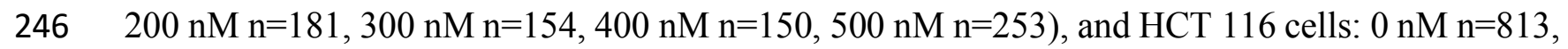

$247100 \mathrm{nM} \mathrm{n}=742,200 \mathrm{nM}$ n=297, $300 \mathrm{nM} \mathrm{n}=296,400 \mathrm{nM} \mathrm{n=314,500nM} \mathrm{n=301} \mathrm{(N=4} \mathrm{experimental}$

248 replicates). To calculate the proportion of cells with different mitotic spindle phenotypes (Figure

$2492 \mathrm{~B}$ and $\mathrm{C}$ ), the following number of HFF-1 cells were counted on average after treatment with

250 DMSO n=28, 300 nM C87 n=24 and 300 nM C75 n=13, HeLa cells after treatment with DMSO

$251 \mathrm{n}=45,300 \mathrm{nM} \mathrm{C87} \mathrm{n}=36$ and $300 \mathrm{nM} \mathrm{C75} \mathrm{n}=109$, A549 cells with DMSO n=29, 300 nM C87

$252 \mathrm{n}=32$ and $300 \mathrm{nM} \mathrm{C75} \mathrm{n}=63$, and HCT 116 cells with DMSO n=41, $300 \mathrm{nM} \mathrm{C87} \mathrm{n=32} \mathrm{and} 300$

$253 \mathrm{nM} \mathrm{C75} \mathrm{n}=66(\mathrm{~N}=3$ experimental replicates). Fewer HFF-1 cells were analyzed compared to the 
254

255

256

257

258

259

260

261

262

263

264

265

266

267

268

269

270

271

272

273

274

275

276

277

278

279

280

281

282

283

284

other cell lines due the low proportion of mitotic cells in the population. To determine the number of centrin-2-positive foci in HeLa cells (Figure 2D), an average of 25 cells were counted for the control (DMSO-treated) and 30 cells after treatment with $300 \mathrm{nM} \mathrm{C75} \mathrm{(N=3} \mathrm{experimental}$ replicates). To calculate changes in the proportion of mitotic spindle phenotypes in HeLa cells after treatment with C75 and/or Colchicine (Figures 3B and C), we counted the following average numbers of cells: DMSO $n=51,20 \mathrm{nM}$ Colchicine $n=62,50 \mathrm{nM}$ Colchicine $n=72,100 \mathrm{nM}$ Colchicine n=78, 100 nM C75 n=42, 200 nM C75 n=46, 300 nM C75 n=59, 400 nM C75 n=69, $500 \mathrm{nM} \mathrm{C75} \mathrm{n}=65,100 \mathrm{nM} \mathrm{C75}+20 \mathrm{nM}$ Colchicine $\mathrm{n}=70,200 \mathrm{nM} \mathrm{C75}+20 \mathrm{nM}$ Colchicine $\mathrm{n}=89,300 \mathrm{nM} \mathrm{C75}+20 \mathrm{nM}$ Colchicine $\mathrm{n}=94,400 \mathrm{nM} \mathrm{C75}+20 \mathrm{nM}$ Colchicine $\mathrm{n}=98$ and $500 \mathrm{nM}$ $\mathrm{C} 75+20 \mathrm{nM}$ Colchicine $\mathrm{n}=83(\mathrm{~N}=3$ experimental replicates). To calculate changes in the proportion of mitotic spindle phenotypes in HCT 116 cells after treatment with C75 and/or Colchicine as above (Figure S3B), we counted the following average number of cells: DMSO $\mathrm{n}=44,20 \mathrm{nM}$ Colchicine $\mathrm{n}=39,50 \mathrm{nM}$ Colchicine $\mathrm{n}=54,100 \mathrm{nM}$ Colchicine $\mathrm{n}=51,100 \mathrm{nM} \mathrm{C75}$ $\mathrm{n}=42,200 \mathrm{nM} \mathrm{C75} \mathrm{n}=40,300 \mathrm{nM} \mathrm{C75} \mathrm{n}=82,400 \mathrm{nM} \mathrm{C75} \mathrm{n}=56,500 \mathrm{nM} \mathrm{C75} \mathrm{n}=65,100 \mathrm{nM} \mathrm{C75}$ $+20 \mathrm{nM}$ Colchicine $\mathrm{n}=43,200 \mathrm{nM} \mathrm{C75}+20 \mathrm{nM}$ Colchicine $\mathrm{n}=52,300 \mathrm{nM} \mathrm{C75}+20 \mathrm{nM}$ Colchicine $\mathrm{n}=69,400 \mathrm{nM} \mathrm{C75}+20 \mathrm{nM}$ Colchicine $\mathrm{n}=76$ and $500 \mathrm{nM} \mathrm{C75}+20 \mathrm{nM}$ Colchicine $\mathrm{n}=81$ ( $\mathrm{N}=3$ experimental replicates). To count the proportion of cells with multipolar or bipolar spindles in HeLa cells after release from C75 or Colchicine (Figure 4B), we counted the following number of average cells: DMSO n=61, $500 \mathrm{nM} \mathrm{C75} n=50$ and $500 \mathrm{nM}$ Colchicine $n=64(\mathrm{~N}=3$ experimental replicates). To determine the proportion of cells with mitotic spindle phenotypes and compare these to ch-TOG RNAi treatment (Figure 6A and B), we counted the following number of average cells: DMSO n=81, $200 \mathrm{nM} \mathrm{C75} n=242,300 \mathrm{nM} \mathrm{C75} n=143$, ch-TOG RNAi $n=534$ ( $\mathrm{N}=3$ experimental replicates).

To determine synergy for the viability of cells treated with C75 and Colchicine in combination, CompuSyn software was used (Figure 3, Figure S3A). We used the non-constant ratio method of analysis since the concentration used for the combination studies was selected based on the highest concentration without lethality. The analysis indicated what combination of drug concentrations yielded an antagonistic, synergistic and additive effect based on the welldocumented combination index (CI) described by the Chou-Talalay method (Chou 2010).

To determine the effect of $\mathrm{C} 75$ on spindle poles, HeLa cells stably expressing GFP:Tubulin and or ch-TOG:GFP; sh ch-TOG were used to measure changes in spindle volume and maximum 
285 intensity after upshift from cold treatment to recover depolymerized microtubules in the presence 286 of C75 or Colchicine. To do this, we used the spot analyzer function in Imaris 9.5.1 (Bitplane),

287 with parameters set to measure local contrast between the spindle pole and surrounding cytosol, 288 which defined the pole boundaries (Supplemental Movies 1-3). Values were exported and 289 organized in csv format using a macro in Python 3.0 to extract the volume and maximum intensity 290 of each pole. The csv files were then imported into GraphPad Prism 7 to build graphical 291 representations, including heat maps, bar graphs and distribution plots. Statistical analyses were 292 also done in GraphPad Prism 7, to determine the significance between slope distributions using 293 the Welch's two-tailed t test with a 99\% confidence interval $(p<0.0001)$. Peaks corresponding to 294 changes in spindle pole volume was determined for each pole using the built-in function 295 "findpeaks" in MatLab R2017b. The parameters were set to identify any peaks that corresponded 296 to a change in volume with an amplitude $>=20 \%$. Identified peaks were then tabulated in Excel 297 (Microsoft) and imported to GraphPad Prism 7 for graphical representation. 


\section{Results}

\section{Compound 75 causes cells to arrest in G2/M phase}

We recently synthesized a new family of thienoisoquinoline compounds and identified several active derivatives that can bind to tubulin in vitro and cause reduced cell viability (manuscript submitted). The structure of Compound 75 (C75) is shown in Figure 1A, along with an inactive derivative C87. C75 prevents microtubule polymerization in vitro at concentrations equal to or above $250 \mathrm{nM}$ (e.g. Fig. 1B) and disrupts previously assembled microtubule polymers (Fig. S1A). These characteristics of C75 are similar to Colchicine, which prevents polymerization in vitro at ranges of 1-5 $\mu \mathrm{M}$, and depolymerizes microtubules (Fig. S1A; Fitzgerald 1976). C75 also binds to the Colchicine-pocket, as it can compete with Colchicine for binding to this site (Fig. S1B; Fitzgerald 1976; Hastie 1991). Together these data suggest that C75 binds to the Colchicinebinding site and prevents polymerization and destabilizes microtubules similar to Colchicine. However, C75 blocks polymerization at lower concentrations compared to Colchicine, suggesting that there are some differences in their accessibility and how they affect microtubules.

Next, we determined if C75 causes mitotic arrest similar to other tubulin-targeting compounds. While the inactive derivative, C87, had little effect on the viability of HFF-1 (human foreskin fibroblast), HeLa (cervical adenocarcinoma), A549 (lung carcinoma), or HCT 116 (colorectal carcinoma) cells, C75 caused reduced viability that varied depending on the cell line (Fig. 1C). While the $\mathrm{IC}_{50}$ for the viability of HeLa, A549 and HCT 116 cells treated with C75 was 427, 377 and $431 \mathrm{nM}$, respectively, it was $789 \mathrm{nM}$ for HFF-1 cells (Fig. 1C). This suggests that cancer cells have $\sim 2$-fold higher sensitivity to C75 compared to fibroblasts. To determine if the reduced viability is caused by cell cycle arrest, we performed flow cytometry on HeLa, A549 and HCT 116 cells after treatment with increasing concentrations of C75 for 8 hours. For all three lines, there was an increase in the proportion of cells in G2/M, and a decrease in G0/G1 (Figs 1D, S2). An ANOVA test followed by a post hoc Tukey's multiple comparison test revealed that there was a significant change in the proportion of $\mathrm{HeLa}$ and A549 cells in G2/M and G0/G1 after treatment with 400 or $500 \mathrm{nM}$ of C75 (Fig. 1D). HCT 116 cells responded at lower concentrations, with 325 significant changes observed after treatment with $200 \mathrm{nM}, 300,400$ and $500 \mathrm{nM}$ of C75 (Fig. 1D). 326 While there was no change in the proportion of HeLa or A549 cells in S phase, there was a decrease in HCT 116 cells in S phase after treatment with $500 \mathrm{nM}$ of C75 (Fig. 1D). To further demonstrate 
329

330

331

332

333

334

335

336

337

338

339

340

341

342

343

344

345

346

347

348

349

350

351

352

353

354

355

356

357

358

centromeres after treatment with 300 or $500 \mathrm{nM} \mathrm{C75}$ and compared to control cells. Indeed, while metaphase HeLa, A549 and HCT 116 cells had bipolar spindles and aligned chromosomes, the spindles in treated cells had reduced microtubule intensity, misaligned chromosomes and fragmented spindle poles (Fig. 1E). Next, we counted the number of rounded, mitotic HeLa, A549 and HCT 116 cells after treatment with varying concentrations of C75 for 24 hours (Fig. 2A). For all cell lines, we saw a dramatic increase in the proportion of mitotic cells at $300 \mathrm{nM}$ (55.7\% HeLa, 76.4\% A549 and 71.7\% HCT 116, respectively). From these data we conclude that C75 is a tubulin-targeting compound that causes mitotic arrest due to aberrant mitotic spindles.

\section{C75 causes spindle pole phenotypes}

As described above, C75 causes spindle phenotypes that increase in severity with concentration. These phenotypes range from reduced microtubules and misaligned chromosomes to fragmented spindle poles. To further quantify the spindle phenotypes caused by C75, HFF-1, HeLa, A549 and HCT 116 cells were treated with 300 nM C75 for 4 hours and stained for DNA, $\gamma$-tubulin and centromeres (Fig. 2B). Cells were treated at a lower vs. higher concentration of C75 and for a shorter period of time ( 4 hours vs. 8 or 24 hours) to capture a broader range of phenotypes. While HFF-1 cells had no obvious change in their spindle morphology, HeLa, A549 and HCT 116 cells showed spindle phenotypes that we classified as monopolar (centrosomes failed to separate), bipolar misaligned (misaligned sister chromatids) and multipolar spindles (fragmented or declustered centrosomes; Figs 2B, C). As determined by multiple t tests, there was a significant increase in HeLa cells with bipolar misaligned (41.1 vs. 7.1\% control) and multipolar spindles (30.6 vs. $7.6 \%$ control), while there was a significant increase in A549 cells with monopolar (5 vs. $0 \%$ control) and multipolar spindles (77.6 vs. 3\% control; Fig. 2C). There was a significant increase in HCT 116 cells with monopolar (34.5 vs. 9.5\% control), bipolar misaligned (21.5 vs. $4.4 \%$ control) and multipolar spindles (12.5 vs. 6.9\% control; Fig. $2 \mathrm{C})$. To determine if multipolar spindles arose due to $\gamma$-tubulin displacement, or due to disruption of more core centrosome components, we repeated this experiment with HeLa cells and stained for DNA, tubulin and centrin-2 (Fig. 2D). Indeed, a significantly greater proportion of C75-treated cells had more than 1 or 2 centrin-2 foci compared to control cells (59 vs. 10\%). Therefore, C75 is capable of displacing centrosome components. The different proportions of spindle phenotypes caused by $\mathrm{C} 75$ in the 
359

different cell lines likely reflects underlying differences in their genetic backgrounds and overall sensitivity to spindle disruption.

\section{Combining C75 and Colchicine enhance spindle phenotypes}

Our data shows that C75 has characteristics similar to Colchicine and can bind to the Colchicine-pocket on tubulin. However, C75 is more effective at preventing polymerization in vitro and it could bind to alternate sites on tubulin. In addition, the two compounds could have different accessibility, or targets in cells. If C75 binds to a different site or target compared to Colchicine, they could have synergistic vs. additive effects when combined. We found that the $\mathrm{IC}_{50}$ for viability of C75 and Colchicine in HeLa cells was $425 \mathrm{nM}$ and $9.5 \mathrm{nM}$, respectively (Fig. 3A). Adding $3 \mathrm{nM}$ of Colchicine, a sub-optimal dose that caused little change in viability, to varying concentrations of $\mathrm{C} 75$ lowered the $\mathrm{IC}_{50}$ for $\mathrm{C} 75$ to $153 \mathrm{nM}$ (Fig. 3A). Similarly, adding $250 \mathrm{nM}$ of C75, which had a minimal impact on viability, to a range of Colchicine concentrations lowered the $\mathrm{IC}_{50}$ for Colchicine to $1.9 \mathrm{nM}$ (Fig. 3A). To ascertain whether the combinatorial treatments were synergistic, additive or antagonistic, we analyzed the data using software for drug combination studies called CompuSyn (Chou 2010). Using the non-constant ratio method, we determined the Combination Index (CI) for each drug combination and found that C75 and Colchicine synergized at concentrations where they typically had low lethality (Fig. S3A). In particular, synergy was observed with $3 \mathrm{nM}$ of colchicine and $300 \mathrm{nM}$ of C75, and when $250 \mathrm{nM}$ C75 was combined with $5 \mathrm{nM}$ Colchicine, with CI values of 0.20 and 0.25 , respectively (Fig. S3A).

Next, we determined the spindle phenotypes caused by combining the two compounds. HeLa cells were treated for 4 hours with 20 or $50 \mathrm{nM}$ Colchicine, or 100, 200 or $300 \mathrm{nM}$ of C75 with or without $20 \mathrm{nM}$ Colchicine. Cells were fixed and stained for DNA, $\gamma$-tubulin and centromeres, and the proportion of cells with bipolar, bipolar misaligned or multipolar spindles was counted for each treatment (Fig. 3B, C). While control (DMSO) and cells treated with $20 \mathrm{nM}$ Colchicine, or $100 \mathrm{nM}$ or $200 \mathrm{nM} \mathrm{C75} \mathrm{had} \mathrm{similar} \mathrm{proportions} \mathrm{of} \mathrm{bipolar} \mathrm{misaligned} \mathrm{or} \mathrm{multipolar}$ spindles, higher concentrations of Colchicine $(50 \mathrm{nM})$ or C75 $(300 \mathrm{nM})$ caused an increase in the proportion of cells with spindle phenotypes (Fig. 3B, C). When $20 \mathrm{nM}$ of Colchicine was added to C75 (100, 200 and $300 \mathrm{nM})$ the proportion of cells with bipolar misaligned and/or multipolar spindles increased (Fig. 3B, C). In particular, combining $20 \mathrm{nM}$ Colchicine with $300 \mathrm{nM} \mathrm{C75}$ caused the multipolar phenotype to increase beyond the sum of each drug on their own at those 
390

391

392

393

394

395

396

397

398

399

400

401

402

403

404

405

406

407

408

409

410

411

412

413

414

415

416

417

418

419

concentrations. A similar enhancement of phenotypes was observed in HCT 116 cells, when 20 nM Colchicine was added with 300 or $400 \mathrm{nM}$ of C75 (Fig. S3B). Therefore, C75 and Colchicine enhance each other's effect in cells, suggesting that they have different binding sites for tubulin, or bind to different targets in cells.

\section{C75 and Colchicine have different effects on microtubule polymers in cells}

Our data shows that $\mathrm{C} 75$ causes mitotic spindle phenotypes, which includes the formation of multipolar spindles. Although C75 acts similarly to Colchicine in vitro, their enhancement in cells suggests that there are differences in their mechanism of action. We characterized spindle phenotypes immediately after adding C75 and compared these to Colchicine. Live metaphase HeLa cells were treated with $300 \mathrm{nM} \mathrm{C75}$ or Colchicine and imaged using live dyes (Hoechst 33342 to visualize chromatin, and SiR-tubulin to visualize tubulin) to monitor spindle phenotypes. The majority of control cells (DMSO-treated) exited mitosis, with bipolar spindles that matured to segregate sister chromatids and form a midbody (14/15), with the exception of one cell where a tripolar spindle formed into a pseudo-bipolar spindle and divided successfully (Fig. 4A). All cells treated with $300 \mathrm{nM}$ Colchicine remained bipolar, and some cells arrested with collapsed spindles (5/20), while others exited mitosis similar to control (15/20; Fig. 4A). Cells treated with $300 \mathrm{nM}$ C75 either arrested in mitosis with bipolar spindles (12/20), or became multipolar (7/20), and a monopolar spindle formed in one cell (1/20; Fig. 4A). In cells treated with either Colchicine or $\mathrm{C} 75$, the microtubules decreased or were lost altogether, but in C75-treated cells, microtubules repolymerized with an uneven distribution between the two poles (Fig. 4A).

Next, we compared how cells recovered from short treatments of $\mathrm{C} 75$ or Colchicine. HeLa cells were treated with $500 \mathrm{nM}$ of $\mathrm{C} 75$ or Colchicine for 5 minutes, then the drugs were washed out, and cells were left to recover in drug-free media for 40 minutes prior to fixing and staining them for DNA and tubulin (Fig. 4B). While the majority of cells recovered with bipolar spindles after Colchicine treatment (79.2\% bipolar vs. $17.7 \%$ multipolar), a significantly larger proportion of cells treated with $\mathrm{C} 75$ had multipolar spindles determined by the multiple $\mathrm{t}$ test (45.7\% bipolar vs. $49.7 \%$ multipolar; Fig. 4B). This data shows that C75 causes different spindle phenotypes compared to Colchicine in cells, although both compounds can prevent microtubule polymerization and cause depolymerization in vitro. 
To further compare the effect of C75 and Colchicine on microtubules in cells, we induced microtubule depolymerization by cold treatment, then monitored their re-growth in the presence

422 of the compounds. To do this we used HeLa cells stably expressing GFP-tagged tubulin, and cold423 treated the cells for 30 minutes in an ice bath. The cells were then upshifted to $37^{\circ} \mathrm{C}$ at which time $424300 \mathrm{nM} \mathrm{C75}$ or Colchicine was added, then the cells were imaged during recovery as shown in 425 Figure 5A. All of the control cells re-formed robust bipolar spindles and were in telophase $\sim 40$ 426 minutes after temperature upshift, indicating that the microtubules recovered and formed a 427 functional mitotic spindle. In the presence of Colchicine, microtubules steadily decreased in intensity, with no detectable GFP signal by 98 minutes (24/24 cells; Fig. 5A). In C75-treated cells, microtubules similarly decreased, but after 20 minutes they polymerized and a GFP signal was detected in all cells (15/15 cells; Fig. 5A). The spindles were disorganized with misaligned sister chromatids, and cells failed to exit mitosis. To further characterize these phenotypes, we quantified changes in spindle pole volume and maximum intensity over time (Figs 5A-D, S4A, B). As expected, Colchicine-treatment caused a decrease in both volume and maximum intensity of the spindle poles over time (Figs 5A-D; S4A, B). Some fluctuation in volume was observed, however, there was a net linear decrease in volume and signal intensity over time as indicated by the bestline fits with negative slopes (Figs 5A, B; S4A, B). Heatmaps show the proportional changes in spindle volume or intensity for each spindle pole, and highlight how each pole decreased over time, albeit some sooner than others (Figs 5D, S4B, Supplemental Movie 1). Unlike Colchicine, C75-treatment caused an initial decrease in spindle pole volume and maximum intensity, followed by subsequent recovery and oscillation (Figs 5A, B; S4A, B). This is more evident in the heatmaps for each spindle pole, where signal intensity and pole volume continued to recover and fluctuate over time (Figs 5D, S4B, Supplemental Movie 2). To better understand this oscillatory pattern in 444 (Fig. 5C). While the majority of spindle poles in Colchicine-treated cells had only 1 or 2 peaks $445(69 \%$ with 1 or 2 vs. $31 \%$ with $>2)$, the majority of poles in C75-treated cells had $>2$ peaks $(46 \%$ 446 with 1 or 2 vs. $54 \%$ with $>2$; Fig. 5C). Thus, C75 causes distinct phenotypes compared to

447 Colchicine, where microtubule growth can recover in the presence of the compound, but this 448 growth is not even between the spindle poles and leads to the formation of disorganized mitotic 449 spindles. 
Depleting ch-TOG, a microtubule polymerase, caused phenotypes similar to C75 (Fig. 6A;

451

452

453

454

455

456

457

458

459

460

461

462

463

464

465

466

467

468

469

470

471

472

473

474

475

476

477

478

479

Barr and Bakal 2015; Gergely et al. 2003). HeLa cells treated with ch-TOG siRNAs had an increase in the proportion of bipolar spindles with misaligned chromosomes (51 vs. 17\% for control) and multipolar or fragmented spindles (42 vs. 8\% for control; Fig. 6A, B). As described earlier, we saw an increase in both phenotypes in cells treated with a mild increase in $\mathrm{C} 75$, from 200 to $300 \mathrm{nM} \mathrm{C75}$ for 4 hours (64 and 22\% bipolar misaligned; 24 and 76\% multipolar, respectively; Fig. 6A, B). Since ch-TOG balances the activity of MCAK, a microtubule depolymerase to control microtubule length, we propose that C75 similarly causes excess microtubule depolymerization (Barr and Bakal 2015; Holmfeldt et al. 2004).

Next, we determined how C75 effects ch-TOG localization. Metaphase HeLa cells coexpressing sh ch-TOG for endogenous knockdown and sh-resistant ch-TOG:GFP were imaged immediately after treatment with $300 \mathrm{nM}$ C75. In control cells, ch-TOG localized to the spindle poles and spindle microtubules, which decreased and was no longer detectable as cells progressed through mitotic exit (e.g. 30 minutes;13/13; Fig. 6C). In cells treated with $300 \mathrm{nM} \mathrm{C75,} \mathrm{ch-TOG}$ increased in intensity at the spindle poles, which moved closer together within 5 minutes, and remained visible for more than 50 minutes (10/10; Fig. 6C). We also observed the accumulation of ch-TOG at a third pole in one of the cells, albeit with lower intensity compared to the other poles (e.g. Fig. 6E; Supplemental Movie 3). Measuring the change in maximum intensity of chTOG at spindle poles within an individual C75-treated cell revealed differences in the signal at one pole relative to the other, which oscillated over time (Fig. 6D). We then measured the intensity of ch-TOG in multiple C75-treated cells, and plotted these values as heatmaps of their maximum values (\%), where purple shows values closest to the maximum, and orange shows the lowest (Fig. $6 \mathrm{E})$. While there was a trend for ch-TOG levels to recover to maximum levels within the first 10 minutes of imaging, we observed reciprocal changes in intensity between the poles as in Figure 6D. To show this more clearly, we made a heat map of the relative changes in intensity from one timepoint to the next, where the colour reflects the increase (purple) or decrease (orange; Fig. 6E). Indeed, for most time points, there were inverse changes in the intensity of ch-TOG at the spindle poles within each cell, which started almost immediately after the addition of C75. This suggests that although ch-TOG accumulates at spindle poles, some pools of ch-TOG are displaced and oscillate between the poles, supporting their instability. 


\section{Discussion}

Here we describe the mechanism of action of C75, a new microtubule-targeting drug, in cultured human cells. C75 can compete with Colchicine for the Colchicine-binding pocket on tubulin and prevents microtubule polymerization in vitro (Figs 1, S1). C75 causes reduced viability and mitotic arrest due to the formation of aberrant spindles similar to other microtubule-targeting drugs including Colchicine (Figs 1, 2, S2). However, C75 has a different effect on microtubules in cells compared to Colchicine (Figs 4-6). For example, in HeLa cells, Colchicine causes a decrease in microtubules followed by gradual collapse of the spindle poles (Fig. 4), and fragmentation of the poles is only observed after long periods of time (e.g. hours vs. minutes; Figs 3, 6). However, C75 causes a decrease in microtubules and spindle pole fragmentation within minutes, followed by microtubule polymerization (Fig. 4). We also observed that tubulin or ch-TOG at the spindle poles oscillate during recovery, leading to the formation of disorganized spindles (Figs 5, 6, S4). In support of their different spindle phenotypes, combining C75 and Colchicine synergistically reduce cell viability and enhance spindle phenotypes when used at low concentrations (Figs 3, S3).

Our findings shed some light on the mechanism of action of C75 and how it affects microtubules in cells. The spindle phenotypes are similar to those caused by the depletion of chTOG, which is a microtubule polymerase (Fig. 6; Gergely et al. 2003; Brouhard et al. 2008; Barr and Bakal 2015). Many MAPs work together to form functional, bipolar spindles (Petry 2016). The loss of ch-TOG presumably causes an imbalance in the activities of other enzymes, including the microtubule depolymerase MCAK. Functions for MCAK include destabilizing microtubule ends to correct kinetochore attachments, which is controlled by Aurora B kinase phosphorylation, and focusing the asters into spindle poles via Aurora A kinase phosphorylation (Andrews et al. 2004; Ems-Mcclung et al. 2013; Walczak et al. 2013; Zhang et al. 2008). ch-TOG-depleted cells

503 have phenotypes consistent with these roles including disorganized spindle poles and misaligned sister chromatids (Gergely et al. 2003). We similarly observed the formation of disorganized

505 spindles and misaligned chromosomes in C75-treated cells. Based on this we speculate that: 1)

506 C75 binds to tubulin dimers in a way that causes depolymerization of microtubules, but has a high

507 off-rate and new polymers can form due to local increases in the critical concentration of free 508 tubulin, and/or 2) C75 disrupts the microtubule or tubulin-binding site(s) of ch-TOG, mimicking 509 ch-TOG loss-of-function. ch-TOG has multiple TOG domains that associate with tubulin dimers 
511 with the microtubule lattice (Widlund et al. 2011; Brouhard et al. 2008). In support of this we

512 observed the accumulation and oscillation of ch-TOG between spindle poles in C75-treated cells

513 (Fig. 6), which could reflect the displacement of ch-TOG from microtubules or tubulin. In addition,

514 the spindle phenotypes caused by C75 are restricted to metaphase, which could reflect its inhibition

515 of an enzyme like ch-TOG with a similar window of requirement.

Another microtubule-targeting compound, Vinblastine, similarly has complex effects on

517 microtubules which could contribute to its success as an anti-cancer drug. In vitro, Vinblastine

518 causes depolymerization at minus ends, and prevents growth at the plus ends (Panda et al., 1996).

519 In cells, 2 or $10 \mathrm{nM}$ of Vinblastine treatment causes disengagement of the mother and daughter

520 centrioles and altered ultra-architecture of centrioles, or reduced microtubule dynamics and

521 multipolar spindles, respectively (Jordan et al., 1992; Levrier et al. 2017; Wendell et al., 1993).

522 We propose that C75 shares some similarities with Vinblastine with an accessibility and/or binding

523 kinetics that favors microtubule depolymerization at the minus ends. But this accessibility appears

524 to be restricted to cells in metaphase, as cells in other stages of the cell cycle do not appear to be

525 affected at similar concentrations. Vinblastine is one of the few microtubule-destabilizing drugs

526 that has been successful in the clinic as an anti-cancer therapy. There are many factors that impact

527 how well a compound functions in vivo, and it is difficult to know what concentrations are reached

528 at the target cells (Hughes et al. 2011). The ability of Vinblastine to cause spindle phenotypes at

529 very low concentrations without disrupting the microtubule polymer mass could be ideal for

530 minimizing side-effects. While $\mathrm{C} 75$ has a high $\mathrm{IC}_{50}$ value by comparison (in the $300-400 \mathrm{nM}$ range

531 for HeLa, HCT 116 and A549 cells), it's unique effect on microtubules and high selectivity for

532 metaphase cells could make it an interesting compound to consider for in vivo use. Importantly,

533 the design of our compound is such that the scaffold is amenable to modifications at three different

534 sites, and we are constantly making new derivatives with improved $\mathrm{IC}_{50}$ values and solubility that

535 would replace C75 as our lead (manuscript submitted).

536 C75 causes spindle pole fragmentation prior to the oscillation of tubulin and ch-TOG at

537 spindle poles. Centrosome integrity has been shown to rely on a TACC3-Clathrin-ch-TOG

538 complex, and many microtubule-targeting drugs lead to the fragmentation of spindle poles,

539 although this typically occurs after an extended period of time likely partly due to mitotic delay

540 (e.g. hours; Foraker et al. 2012; Jordan et al. 1992; Karki and Shuster 2017). As mentioned above,

541 low concentrations of Vinblastine cause disengagement of mother-daughter centrioles. In addition, 
542 cancer cells with high aneuploidy and amplified centrosomes typically rely on centrosome

543 clustering mechanisms to form bipolar spindles (Leber et al. 2010; Ogden et al. 2012; Sabat-

544 Pospiech et al. 2019). C75 may promote de-clustering and loss of centrosome integrity as

545 visualized by gamma-tubulin and centrin-2 staining, making it an attractive compound to explore

546 for the treatment of cancers with high centrosome numbers (Sabat-Pospiech et al. 2019). Indeed,

547 different cancer cell lines have different proportions of cells with multipolar spindles after C75

548 treatment, presumably due to different genetic changes in their background including those that

549 could impact centrosome integrity, clustering and/or microtubule dynamics (Fig. 2). We saw an

550 increase in the proportion of A549 and HeLa cells with multipolar spindles, even at lower

551 concentrations, suggesting that they are susceptible to de-clustering or fragmentation.

552 Interestingly, we saw an increase in the proportion of HCT 116 cells with monopolar spindles at

553 lower concentrations. With increased expression of Aurora A kinase and ch-TOG, these cells have

554 increased assembly rates that could suppress C75 at lower concentrations (Ertych et al., 2014). The

555 tendency of spindle poles to move closer together was observed in other cell types, but only after

556 extensive microtubule depolymerization. Identifying specific genetic changes and correlating this

557 with amplified centrosomes, or altered microtubule dynamics or regulation could predict how cells

558 respond to C75-treatment. 


\section{References}

Akhmanova, Anna, and Michel O. Steinmetz. 2015. "Control of Microtubule Organization and Dynamics: Two Ends in the Limelight." Nature Reviews Molecular Cell Biology 16 (12): 711-26. https://doi.org/10.1038/nrm4084.

Al-Bassam, Jawdat, and Fred Chang. 2011. "Regulation of Microtubule Dynamics by TOG-Domain Proteins XMAP215/Dis1 and CLASP.” Trends in Cell Biology 21 (10): 604-14. https://doi.org/10.1016/j.tcb.2011.06.007.

Andrews, Paul D., Yulia Ovechkina, Nick Morrice, Michael Wagenbach, Karen Duncan, Linda Wordeman, and Jason R. Swedlow. 2004. “Aurora B Regulates MCAK at the Mitotic Centromere.” Developmental Cell 6 (2): 253-68. https://doi.org/10.1016/S1534-5807(04)00025-5.

Barr, A. R., and F. Gergely. 2008. "MCAK-Independent Functions of Ch-Tog/XMAP215 in Microtubule Plus-End Dynamics." Molecular and Cellular Biology 28 (23): 7199-7211. https://doi.org/10.1128/mcb.01040-08.

Barr, Alexis R, and Chris Bakal. 2015. "A Sensitised RNAi Screen Reveals a Ch-TOG Genetic Interaction Network Required for Spindle Assembly.” Scientific Reports 5 (April): 10564. https://doi.org/10.1038/srep10564.

Borisy, G. G., and E. W. Taylor. 1967. "The Mechanism of Action of Colchicine. Colchicine Binding to Sea Urchin Eggs and the Mitotic Apparatus.” The Journal of Cell Biology 34 (2): 535-48. https://doi.org/10.1083/jcb.34.2.535.

Brito, D, and CL Rieder. 2010. "The Ability to Survive Mitosis in the Presence of Microtubule Poisons" 66 (8): 437-47. https://doi.org/10.1002/cm.20316.The.

Brouhard, Gary J., Stear, Jeffrey H., Noetzel, Tim L. 2008. "XMAP215 Is a Processive Microtubule Polymerase." Growth (Lakeland) 23 (1): 1-7. https://doi.org/10.1038/jid.2014.371.

Brouhard, Gary J., and Luke M. Rice. 2018. "Microtubule Dynamics: An Interplay of Biochemistry and Mechanics.” Nature Reviews Molecular Cell Biology 19 (7): 451-63. https://doi.org/10.1038/s41580-0180009-y.

Byrnes, Amy E., and Kevin C. Slep. 2017. "TOG-Tubulin Binding Specificity Promotes Microtubule Dynamics and Mitotic Spindle Formation.” The Journal of Cell Biology. http://jcb.rupress.org/content/early/2017/05/15/jcb.201610090.

Chen, Fei, Nicholas W.Y. Wong, and Pat Forgione. 2014. "One-Pot Tandem Palladium-Catalyzed Decarboxylative Cross-Coupling and C-H Activation Route to Thienoisoquinolines." Advanced Synthesis and Catalysis 356 (8): 1725-30. https://doi.org/10.1002/adsc.201300924.

Chou, Ting Chao. 2010. "Drug Combination Studies and Their Synergy Quantification Using the Chou-Talalay Method." Cancer Research 70 (2): 440-46. https://doi.org/10.1158/0008-5472.CAN-09-1947.

Cirillo, Luca, Monica Gotta, and Patrick Meraldi. 2017. Cell Division Machinery and Disease. Vol. 1002. https://doi.org/10.1007/978-3-319-57127-0.

Dominguez-Brauer, Carmen, Kelsie L. Thu, Jacqueline M. Mason, Heiko Blaser, Mark R. Bray, and Tak W. Mak. 2015. “Targeting Mitosis in Cancer: Emerging Strategies.” Molecular Cell 60 (4): 524-36. https://doi.org/10.1016/j.molcel.2015.11.006. 
Ems-Mcclung, Stephanie C., Sarah G. Hainline, Jenna Devare, Hailing Zong, Shang Cai, Stephanie K. Carnes,

Sidney L. Shaw, and Claire E. Walczak. 2013. “Aurora B Inhibits MCAK Activity through a Phosphoconformational Switch That Reduces Microtubule Association.” Current Biology 23 (24): 2491-99. https://doi.org/10.1016/j.cub.2013.10.054.

Field, Jessica J., Arun Kanakkanthara, and John H. Miller. 2015. "Microtubule-Targeting Agents Are Clinically Successful Due to Both Mitotic and Interphase Impairment of Microtubule Function.” Bioorganic and Medicinal Chemistry 22 (18): 5050-59. https://doi.org/10.1016/j.bmc.2014.02.035.

Fielding, AB, S Lim, K Montgomery, I Dobreva, and S Dedhar. 2011. "A Critical Role of Integrin-Linked Kinase, Ch-TOG and TACC3 in Centrosome Clustering in Cancer Cells." Oncogene 30 (5): 521-34. https://doi.org/10.1038/onc.2010.431.

Fitzgerald, Thomas J. 1976. "Molecular Features of Colchicine Associated with Antimitotic Activity and Inhibition of Tubulin Polymerization." Biochemical Pharmacology 25: 1383-87.

Foraker, Amy B., Stéphane M. Camus, Timothy M. Evans, Sophia R. Majeed, Chih Ying Chen, Sabrina B. Taner,

Gergely, Fanni, Viji M. Draviam, and Jordan W. Raff. 2003. "The Ch-TOG/XMAP215 Protein Is Essential for Spindle Pole Organization in Human Somatic Cells." Genes and Development 17 (3): 336-41. https://doi.org/10.1101/gad.245603.

Gigant, Benoît, Chunguang Wang, Raimond B.G. Ravelli, Fanny Roussi, Michel O. Steinmetz, Patrick A. Curmi, André Sobel, and Marcel Knossow. 2005. "Structural Basis for the Regulation of Tubulin by Vinblastine." Nature 435 (7041): 519-22. https://doi.org/10.1038/nature03566.

Goodson, Holly V, and Erin M Jonasson. 2018. "Microtubules and Microtubule-Associated Proteins."

Hanahan, Douglas, and Robert A. Weinberg. 2011. "Hallmarks of Cancer: The next Generation.” Cell 144 (5): 64674. https://doi.org/10.1016/j.cell.2011.02.013.

Hastie, Susan Bane. 1991. "Interactions of Colchicine with Tubulin.” Pharmacology and Therapeutics 51 (3): 377401. https://doi.org/10.1016/0163-7258(91)90067-V.

Holmfeldt, Per, Sonja Stenmark, and Martin Gullberg. 2004. "Differential Functional Interplay of TOGp/XMAP215 and the KinI Kinesin MCAK during Interphase and Mitosis.” EMBO Journal 23 (3): 627-37. https://doi.org/10.1038/sj.emboj.7600076.

Hood, Fiona E., Samantha J. Williams, Selena G. Burgess, Mark W. Richards, Daniel Roth, Anne Straube, Mark Pfuhl, Richard Bayliss, and Stephen J. Royle. 2013. "Coordination of Adjacent Domains Mediates TACC3Ch-TOG-Clathrin Assembly and Mitotic Spindle Binding.” Journal of Cell Biology 202 (3): 463-78. https://doi.org/10.1083/jcb.201211127.

Hughes, J. P., S. S. Rees, S. B. Kalindjian, and K. L. Philpott. 2011. "Principles of Early Drug Discovery.” British Journal of Pharmacology 162 (6): 1239-49. https://doi.org/10.1111/j.1476-5381.2010.01127.x.

Jordan, M. A., D. Thrower, and L. Wilson. 1992. "Effects of Vinblastine, Podophyllotoxin and Nocodazole on 

(3): 401-16.

Jordan, Mary, and Kathy Kamath. 2007. "How Do Microtubule-Targeted Drugs Work? An Overview." Current Cancer Drug Targets 7 (8): 730-42. https://doi.org/10.2174/156800907783220417.

Karki, Menuka, Neda Keyhaninejad, and Charles B. Shuster. 2017. "Precocious Centriole Disengagement and Centrosome Fragmentation Induced by Mitotic Delay.” Nature Communications 8 (May): 1-12. https://doi.org/10.1038/ncomms15803.

Kavallaris, Maria. 2010. "Microtubules and Resistance to Tubulin-Binding Agents." Nature Reviews Cancer 10 (3): 194-204. https://doi.org/10.1038/nrc2803.

Kozielski, Frank. 2015. "Kinesins and Cancer." Kinesins and Cancer 12 (August): 1-271. https://doi.org/10.1007/978-94-017-9732-0.

Kumar, Ashok, Parduman R. Sharma, and Dilip M. Mondhe. 2016. "Potential Anticancer Role of Colchicine-Based Derivatives: An Overview." Anti-Cancer Drugs 28 (3): 250-62. https://doi.org/10.1097/CAD.0000000000000464.

Kumar, N. 1981. “Taxol-Induced Polymerization of Purified Tubulin. Mechanism of Action.” Journal of Biological Chemistry 256 (20): 10435-41.

Leber, Blanka, Bettina Maier, Florian Fuchs, Jing Chi, Phillip Riffel, Simon Anderhub, Ludmila Wagner, et al. 2010. "Proteins Required for Centrosome Clustering in Cancer Cells." Science Translational Medicine 2 (33): 33ra38. https://doi.org/10.1126/scitranslmed.3000915.

Levrier, Claire, Martin C. Sadowski, Anja Rockstroh, Brian Gabrielli, Maria Kavallaris, Melanie Lehman, Rohan A. Davis, and Colleen C. Nelson. 2017. "6$\alpha$-Acetoxyanopterine: A Novel Structure Class of Mitotic Inhibitor Disrupting Microtubule Dynamics in Prostate Cancer Cells.” Molecular Cancer Therapeutics 16 (1): 3-15. https://doi.org/10.1158/1535-7163.MCT-16-0325.

Martin, Maud, and Anna Akhmanova. 2018. "Coming into Focus: Mechanisms of Microtubule Minus-End Organization." Trends in Cell Biology 28 (7): 574-88. https://doi.org/10.1016/j.tcb.2018.02.011.

Martino, Emanuela, Giuseppe Casamassima, Sonia Castiglione, Edoardo Cellupica, Serena Pantalone, Francesca Papagni, Marta Rui, Angela Marika Siciliano, and Simona Collina. 2018. "Vinca Alkaloids and Analogues as Anti-Cancer Agents: Looking Back, Peering Ahead.” Bioorganic and Medicinal Chemistry Letters 28 (17): 2816-26. https://doi.org/10.1016/j.bmcl.2018.06.044.

Massarotti, Alberto, Antonio Coluccia, Romano Silvestri, Giovanni Sorba, and Andrea Brancale. 2012. "The Tubulin Colchicine Domain: A Molecular Modeling Perspective.” ChemMedChem 7 (1): 33-42. https://doi.org/10.1002/cmdc.201100361.

Musacchio, Andrea. 2015. "The Molecular Biology of Spindle Assembly Checkpoint Signaling Dynamics." Current Biology 25 (20): R1002-18. https://doi.org/10.1016/j.cub.2015.08.051.

Oakley, B. R., V. Paolillo, and Y. Zheng. 2015. " $\gamma$-Tubulin Complexes in Microtubule Nucleation and Beyond." Molecular Biology of the Cell 26 (17): 2957-62. https://doi.org/10.1091/mbc.E14-11-1514.

Ogden, a, P C G Rida, and R Aneja. 2012. "Let's Huddle to Prevent a Muddle: Centrosome Declustering as an 
Attractive Anticancer Strategy." Cell Death and Differentiation 19 (8): 1255-67. https://doi.org/10.1038/cdd.2012.61.

Parness, J., and S. B. Horwitz. 1981. "Taxol Binds to Polymerized Tubulin in Vitro.” Journal of Cell Biology 91 (2 I): 479-87. https://doi.org/10.1083/jcb.91.2.479.

Petry, Sabine. 2016. "Mechanisms of Mitotic Spindle Assembly Sabine." Annu Rev Biochem. 85 (1): 659-83. https://doi.org/10.1146/annurev-biochem-060815-014528.

Sabat-Pospiech, Dorota, Kim Fabian-Kolpanowicz, Ian A. Prior, Judy M. Coulson, and Andrew B. Fielding. 2019. “Targeting Centrosome Amplification, an Achilles' Heel of Cancer.” Biochemical Society Transactions 47 (5): 1209-22. https://doi.org/10.1042/BST20190034.

Walczak, Claire E., Sophia Gayek, and Ryoma Ohi. 2013. "Microtubule-Depolymerizing Kinesins." Annual Review of Cell and Developmental Biology 29: 417-41. https://doi.org/10.1146/annurev-cellbio-101512-122345.

Wang, Yuxi, Hang Zhang, Benoît Gigant, Yamei Yu, Yangping Wu, Xiangzheng Chen, Qinhuai Lai, Zhaoya Yang, Qiang Chen, and Jinliang Yang. 2016. "Structures of a Diverse Set of Colchicine Binding Site Inhibitors in Complex with Tubulin Provide a Rationale for Drug Discovery." FEBS Journal 283 (1): 102-11. https://doi.org/10.1111/febs.13555.

Weaver, Beth A. 2014. "How Taxol/Paclitaxel Kills Cancer Cells.” Molecular Biology of the Cell 25 (18): 2677-81. https://doi.org/10.1091/mbc.E14-04-0916.

Widlund, Per O., Jeffrey H. Stear, Andrei Pozniakovsky, Marija Zanic, Simone Reber, Gary J. Brouhard, Anthony A. Hyman, and Jonathon Howard. 2011. "XMAP215 Polymerase Activity Is Built by Combining Multiple Tubulin-Binding TOG Domains and a Basic Lattice-Binding Region.” Proceedings of the National Academy of Sciences of the United States of America 108 (7): 2741-46. https://doi.org/10.1073/pnas.1016498108.

Wordeman, Linda. 2019. “GTP-Tubulin Loves Microtubule plus Ends but Marries the Minus Ends.” Journal of Cell Biology 218 (9): 2822-23. https://doi.org/10.1083/jcb.201908039.

Yu, Jun Xiong, Qian Chen, Ya Qun Yu, Shu Qun Li, and Jian Fei Song. 2016. "Upregulation of Colonic and Hepatic Tumor Overexpressed Gene Is Significantly Associated with the Unfavorable Prognosis Marker of Human Hepatocellular Carcinoma." American Journal of Cancer Research 6 (3): 690-700.

Zasadil, Lauren M, Kristen A Andersen, Dabin Yeum, Gabrielle B Rocque, Lee G Wilke, Amye J Tevaarwerk, Ronald T Raines, Mark E Burkard, and Beth A Weaver. 2014. "Cytotoxicity of Paclitaxel in Breast Cancer Is Due to Chromosome Missegregation on Multipolar Spindles." Science Translational Medicine 6 (229): 229ra43. https://doi.org/10.1126/scitranslmed.3007965.

Zhang, Xin, Stephanie C. Ems-McClung, and Claire E. Walczak. 2008. "Aurora A Phosphorylates MCAK to Control Ran-Dependent Spindle Bipolarity.” Molecular Biology of the Cell 19 (July): 2752-65. https://doi.org/10.1091/mbc.e08-02-0198. 


\section{Figure Legends}

705

706

707

708

709

710

711

712

713

714

715

716

717

718

719

720

721

722

723

724

725

726

727

728

729

730

731

732

733

734

\section{Figure 1. C75 is a thienoisoquinoline compound that causes G2/M arrest in cultured human}

cells. A) The structures of C75 and C87, a derivative with minimal activity, are shown. B) A graph shows the polymerization of microtubules in vitro, measured by changes in absorbance at $320 \mathrm{~nm}$ (X-axis) over time (minutes; Y-axis). Tubulin was polymerized in the presence of $250 \mathrm{nM} \mathrm{C75} \mathrm{or}$ DMSO (control). C) A table shows the IC $_{50}$ for the viability of HFF-1, HeLa, A549 and HCT 116 over three population doubling times after treatment with $\mathrm{C} 75$ or $\mathrm{C} 87(\mathrm{~N}=3)$. D) Bar graphs show the distribution of cells in G0/G1, S and G2/M phases of the cell cycle measured by flow cytometry, for HeLa, A549 and HCT116 cells treated with increasing concentrations of C75 for 8 hours $(n=20,000$ cells per treatment; $N=3$ experimental replicates). Asterisks indicate statistical significance using two-way ANOVA test and post-hoc Tukey's multiple comparison test with a 95\% CI, multiplicity adjusted $p=<0.0004$. E) Images show fixed HeLa, A549 and HCT116 cells immunostained for DNA (DAPI; blue), tubulin (green), and centromeres (ACA; red) after treatment with 300 or $500 \mathrm{nM}$ of $\mathrm{C} 75$ for 8 hours. The scale bar is $10 \mu \mathrm{m}$.

Figure 2. C75 causes multipolar spindles and mitotic arrest. A) A line graph shows changes in the proportion of mitotic HeLa, A549 and HCT 116 cells after treatment with increasing concentrations of $\mathrm{C} 75$ for 24 hours. Asterisks indicate statistical significance using two-way ANOVA test and post-hoc Tukey's multiple comparison test with a 99\% CI; a single asterisk means that HCT 116 is significantly different than HeLa and A549 (multiplicity adjusted $p=$ 0.0007 and $p<0.0001$, respectively), two indicates that HeLa is significantly different than A549 and HCT 116 (multiplicity adjusted $p<0.0001$ for both), and three indicates that HeLa is significantly different than A549 (multiplicity adjusted $p=0.0035$ ). B) Images show fixed HFF 1 , HeLa, A549 and HCT116 cells stained for DNA (DAPI; blue), gamma-tubulin (green), and centromeres (ACA; red) after treatment with $300 \mathrm{nM}$ of $\mathrm{C} 75$ for 4 hours. Cartoon schematics (green circles, centrosomes; blue, chromatin; green lines, microtubules; red, centromeres) show the different phenotypes observed, including bipolar spindles with aligned chromosomes (top), bipolar spindles with misaligned chromosomes (second from top), multipolar spindles (third from top), or monopolar spindles (bottom). The proportion of cells with each phenotype is shown in the top right corner of each image. The scale bar is $10 \mu \mathrm{m}$. C) A bar graph shows the proportion of each spindle phenotype (bipolar aligned in light grey; bipolar misaligned in dark grey; multipolar 
in red; monopolar in black) for HFF 1, HeLa, A549 and HCT 116 cells treated as in B. Bars show standard deviation and asterisks indicate two-way ANOVA test and a post-hoc Tukey's multiple comparison test with a 99\% CI, and multiplicity adjusted $p=<0.001$ for each phenotype vs. DMSO and C87. D) A bar graph shows the proportion of HeLa cells with 1 (black), 2 (dark grey) or more (red) centrin-2 foci after treatment with DMSO or $300 \mathrm{nM} \mathrm{C75.} \mathrm{Cells} \mathrm{were} \mathrm{fixed} \mathrm{and} \mathrm{stained} \mathrm{for}$ DNA (DAPI; blue), tubulin (green), and centrin-2 (red). Asterisks indicate statistical significance of C75 with 2 foci and $>2$ foci compared to DMSO using Multiple $t$ test with a 95\% CI with a multiplicity adjusted $p=0.0009$ and $p=0.0031$, respectively. The scale bar is $10 \mu \mathrm{m}$.

Figure 3. Combining C75 with Colchicine enhances lethality and spindle phenotypes. A) Line graphs show the $\mathrm{IC}_{50}$ for the viability (dotted black lines) of HeLa cells treated with varying concentrations of $\mathrm{C} 75$, Colchicine, or both after three population doubling times as indicated. The graph on the left shows changes in viability (Y-axis) with increasing C75 concentrations (X-axis; black line), Colchicine (dotted orange line), and C75 with $3 \mathrm{nM}$ Colchicine (blue line). The graph on the right shows the changes in viability with Colchicine and $250 \mathrm{nM} \mathrm{C75}$ (green dotted line). The bars indicate $\mathrm{SEM}$, for $\mathrm{N}=3$ experimental replicates. B) Images show fixed HeLa cells stained for DNA (DAPI; blue), gamma-tubulin (green) and ACA (centromeres; red) after treatment for 5 hours with Colchicine, C75 or both. On the images are the proportion of cells with bipolar spindles, and aligned chromosomes (control, DMSO or $20 \mathrm{nM}$ Colchicine), or misaligned chromosomes and multipolar spindles (50 nM Colchicine, $300 \mathrm{nM} \mathrm{C75}$ or both). The scale bar is $10 \mu \mathrm{m}$. C) Bar graphs show the proportion of HeLa cells from B) with bipolar aligned (light grey), bipolar misaligned (dark grey), multipolar (red) or monopolar (black) spindles. Bars show standard deviation. Statistical analysis was done using two-way ANOVA test and a post-hoc Tukey's multiple comparison test with a 90\% CI, and multiplicity adjusted $p=<0.0831$; a single asterisk indicates significance to the Control (DMSO) and two indicates significance to C75. live HeLa cells co-stained for DNA (Hoechst 33342; blue) and microtubules (SiR-tubulin; green).

763 Times are indicated in minutes. An arrow points to the time of addition of $300 \mathrm{nM}$ of C75 (n=21), $764300 \mathrm{nM}$ of Colchicine $(\mathrm{n}=18)$ or DMSO (control; $\mathrm{n}=17)$. The proportion of cells with bipolar, 
were treated with drug (DMSO, $500 \mathrm{nM} \mathrm{C75}$ or Colchicine) for 5 minutes, then fixed 40 minutes after the drugs were washed out. Underneath, images show fixed HeLa cells co-stained for DNA (DAPI; blue) and tubulin (green or white) after treatment with C75 or Colchicine. To the right, a bar graph shows the proportion of cells with monopolar (black), bipolar (dark grey) or multipolar (red) spindles. Bars show standard deviation and asterisks indicate $p<0.05$ by multiple t tests vs. control. The scale bar for all cells is $10 \mu \mathrm{m}$.

Figure 5. Microtubules and spindle poles recover in the presence of C75. A) A cartoon minutes in an ice bath to collapse microtubules, then upshifted to $37^{\circ} \mathrm{C}$ and imaged for microtubule regrowth in the presence or absence of $300 \mathrm{nM} \mathrm{C75}$ or Colchicine. Timelapse images show live HeLa cells stably expressing GFP:tubulin (green) and co-stained for DNA by Hoechst (blue), with the times indicated in minutes. DMSO (control, $n=6)$, Colchicine $(n=24)$ or C75 $(n=15)$ was added at 0 minutes. To the right, line graphs show changes in spindle pole volume (\%; Y-axis) over time (X-axis) after addition of Colchicine or C75 (dotted line indicates best-fit). B) A scatter plot shows the distribution of slope values obtained from best-fit line graphs (Y-axis) for the changes in each spindle pole volume over time after treatment with C75 or Colchicine as in A). Significance was determined using the two-tailed Welch's t test, $p<0.0001$. C) A bar graph shows the number of peaks (X-axis) with an amplitude equal to or greater than $20 \%$ of the maximum volume of the spindle pole after treatment with C75 or Colchicine (Y-axis). D) Heat maps show the change in volume (\%) of individual spindle poles over time (at the top in minutes) in cells treated with Colchicine or C75 as in A). Purple indicates larger volumes while orange indicates smaller volumes. Each line indicates a different spindle pole.

Figure 6. ch-TOG knockdown phenocopies C75, and ch-TOG oscillates in C75-treated cells.

A) Images show fixed HeLa cells stained for DNA (DAPI, blue) and microtubules (tubulin, green) after treatment with ch-TOG siRNAs or 4 hours with C75 as indicated. The proportion of cells with bipolar spindles and aligned chromosomes, bipolar spindles with misaligned chromosomes, or multipolar spindles is indicated on the images. The scale bar is $10 \mu \mathrm{m}$. B) A bar graph shows the proportion of cells (\%) with bipolar spindles (black), bipolar spindles with misaligned chromosomes (dark grey) or multipolar spindles (red) as in A. Bars show standard deviation. 
797 Asterisks show $p<0.0001$ with respect to Control (DMSO) using two-way ANOVA with a 99\%

798 confidence interval. C) Timelapse images show live HeLa cells expressing ch-TOG:GFP (green)

799 in the presence $(n=10)$ or absence of $C 75(n=13)$. Times are indicated in minutes. The scale bar

800 for all cells is $10 \mu \mathrm{m}$. D) A line graph shows the change in ch-TOG:GFP signal intensity (\%, Y-

801 axis) over time (minutes, $\mathrm{X}$-axis) for each pole in an individual cell after $\mathrm{C} 75$ treatment as in $\mathrm{C}$ ).

802 E) A heat map show the change in intensity of ch-TOG:GFP (\%) at the spindle poles. Times are

803 indicated above, with timepoints from 1-11 in increments of 1 minute, and the remainder in 804 increments of 5 minutes (separated by the blue dotted line). F) A heat map shows the relative 805 change in intensity between two adjacent timepoints (\%) after C75-treatment. Times are indicated 806 above, with the same scale as in E). For both heat maps, purple indicates larger values, while 807 orange indicates smaller values. The poles from the same cell are plotted together, and separated 808 by cells via lines. 
bioRxiv preprint doi: https://doi.org/10.1101/2020.08.14.251058; this version posted August 14, 2020. The copyright holder for this preprint (which was not certified by peer review) is the author/funder, who has granted bioRxiv a license to display the preprint in perpetuity. It is made available under aCC-BY-NC 4.0 International license.

A
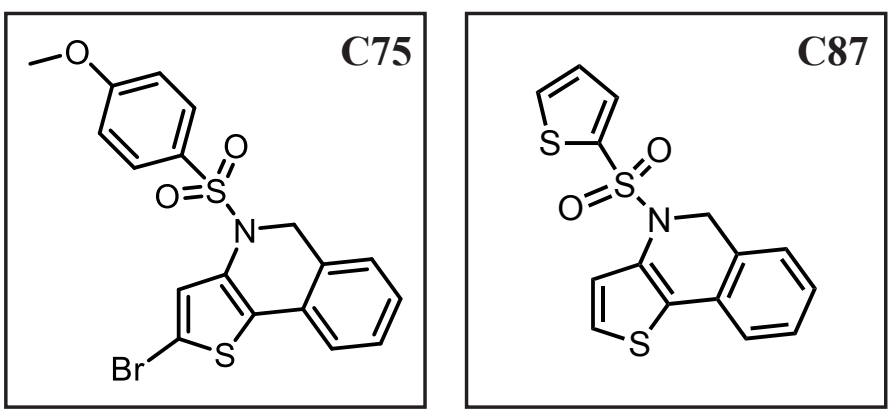

C

\begin{tabular}{|c|c|c|}
\cline { 2 - 3 } \multicolumn{1}{c|}{} & \multicolumn{2}{c|}{ Viability $\mathbf{~ I C}_{\text {50 }}, \mathbf{n M}$} \\
\hline Cell Lines & C75 & C87 \\
\hline HFF-1 & 789 & $>1000$ \\
\hline HeLa & 427 & $>1000$ \\
\hline A549 & 377 & $>1000$ \\
\hline HCT 116 & 431 & $>1000$ \\
\hline
\end{tabular}

E

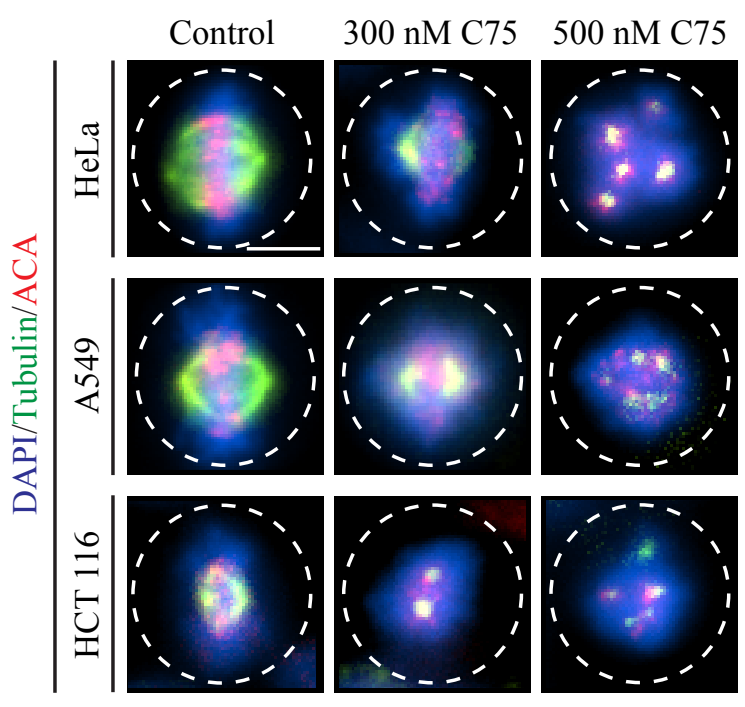

B

Microtubule polymerization

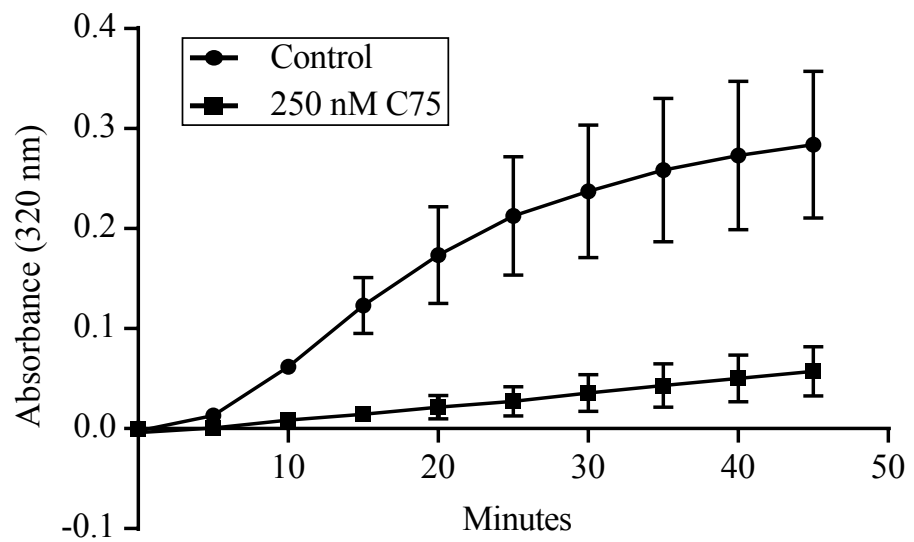

D
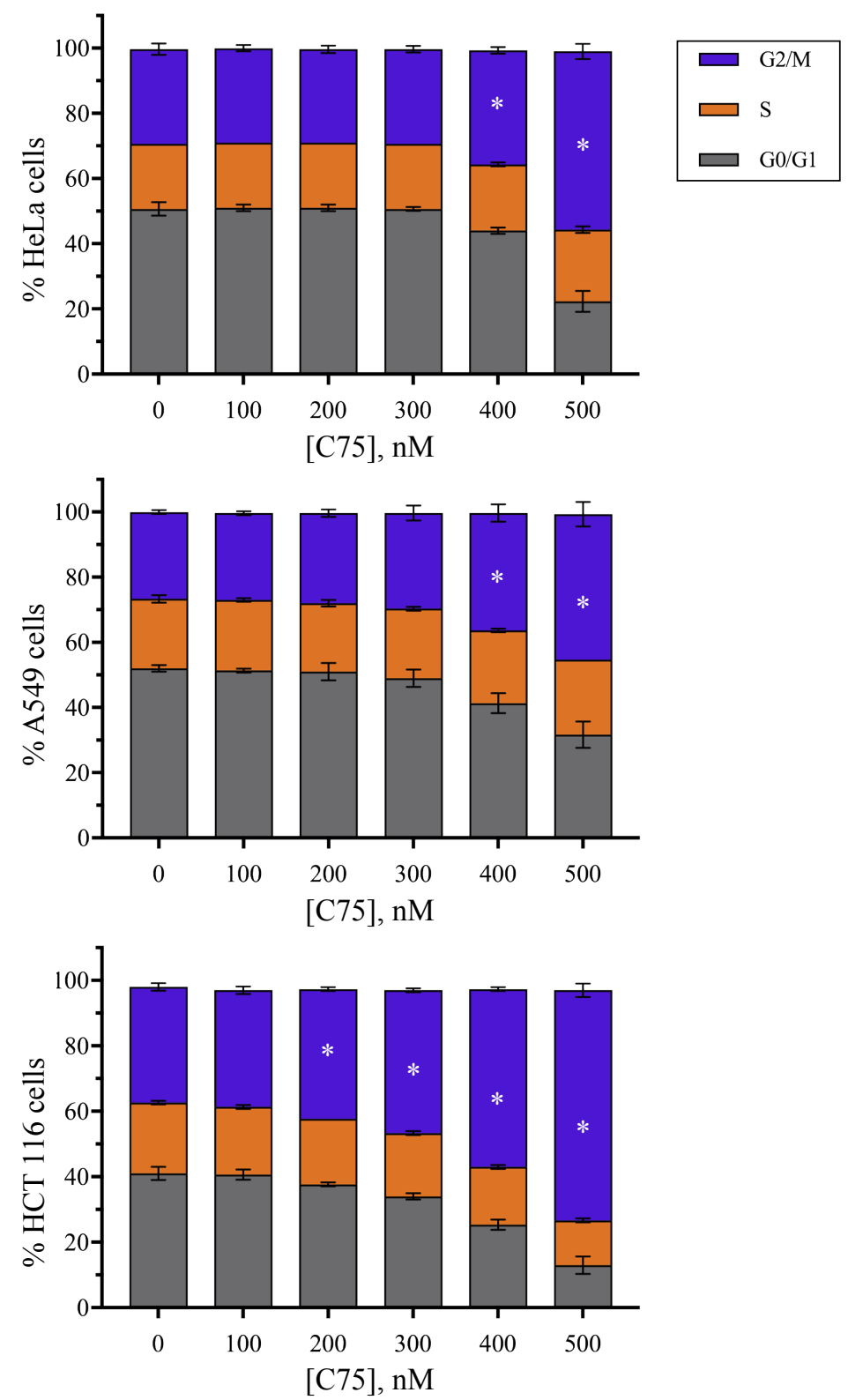
bioRxiv preprint doi: https://doi.org/10.1101/2020.08.14.251058; this version posted August 14, 2020. The copyright holder for this preprint (which was not certified by peer review) is the author/funder, who has granted bioRxiv a license to display the preprint in perpetuity. It is made
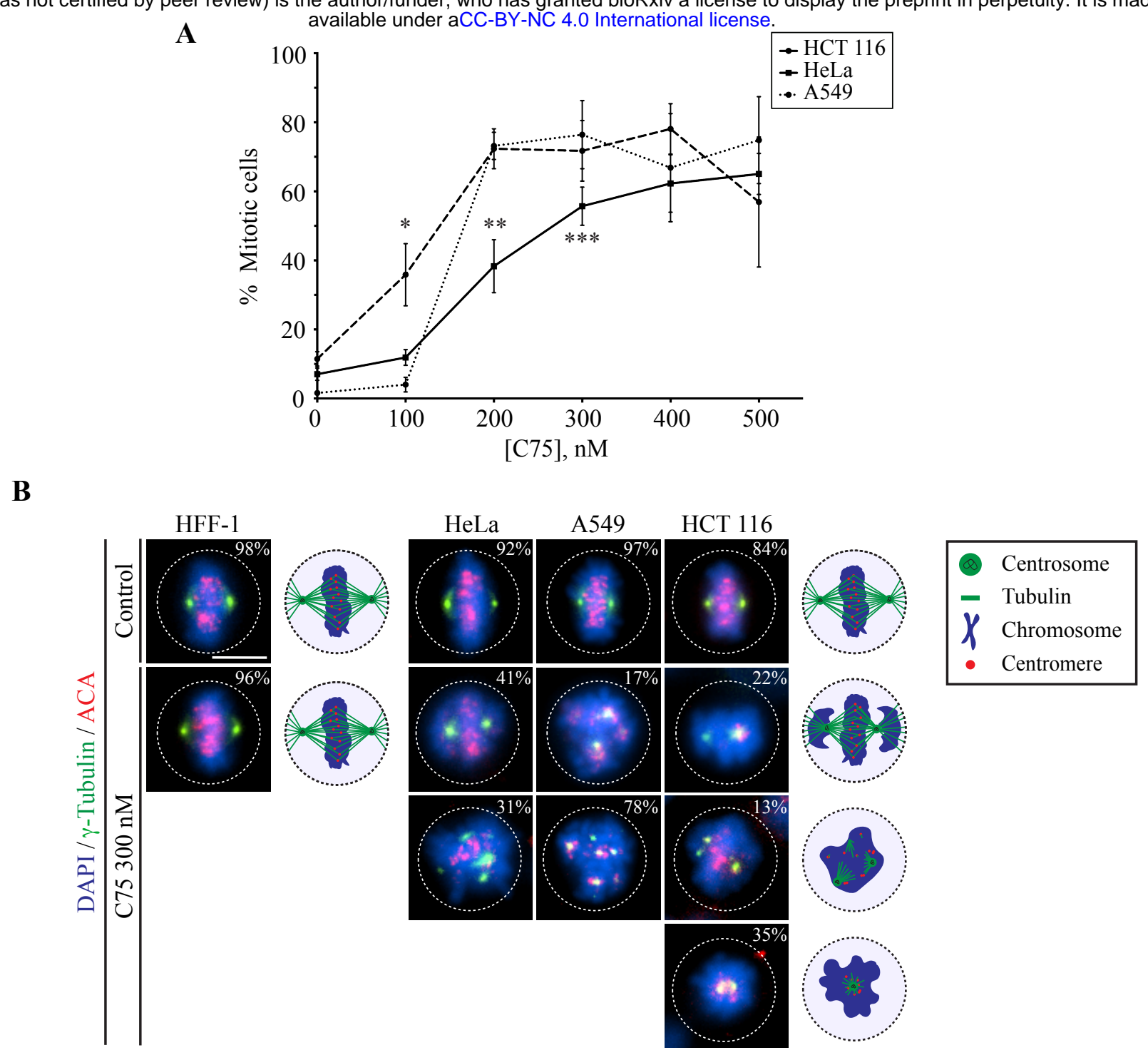

C

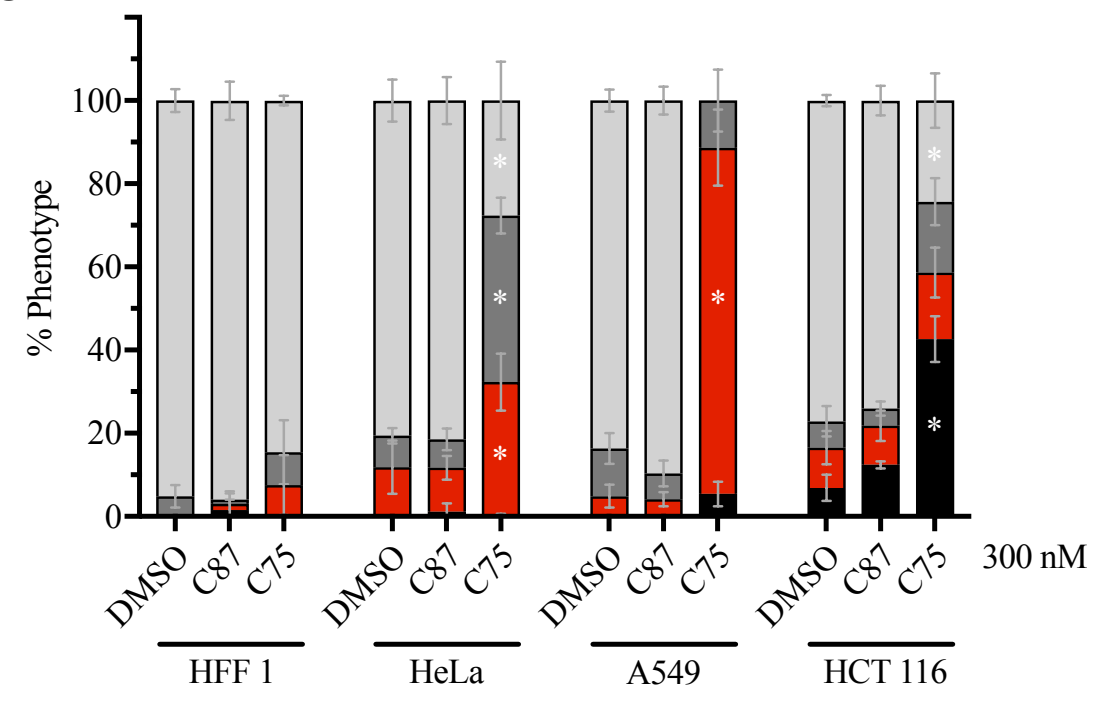

D

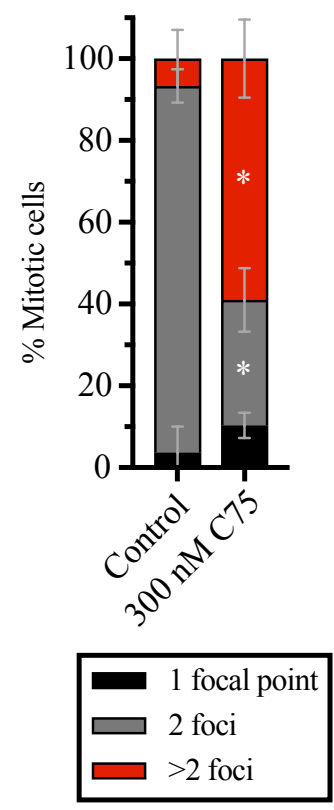

$\underline{\text { DAPI/Tubulin/Centrin-2 }}$

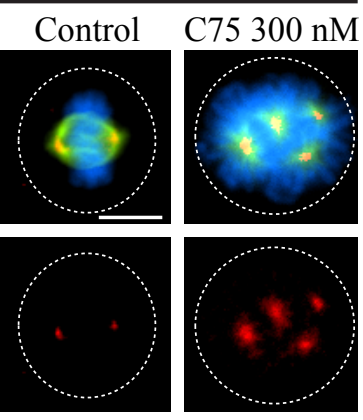

\begin{tabular}{|llll|}
$\square$ & Monopolar & $\square$ & Bipolar aligned \\
$\square$ & Bipolar misaligned & $\square$ & Multipolar \\
\hline
\end{tabular}



available under aCC-BY-NC 4.0 International license.
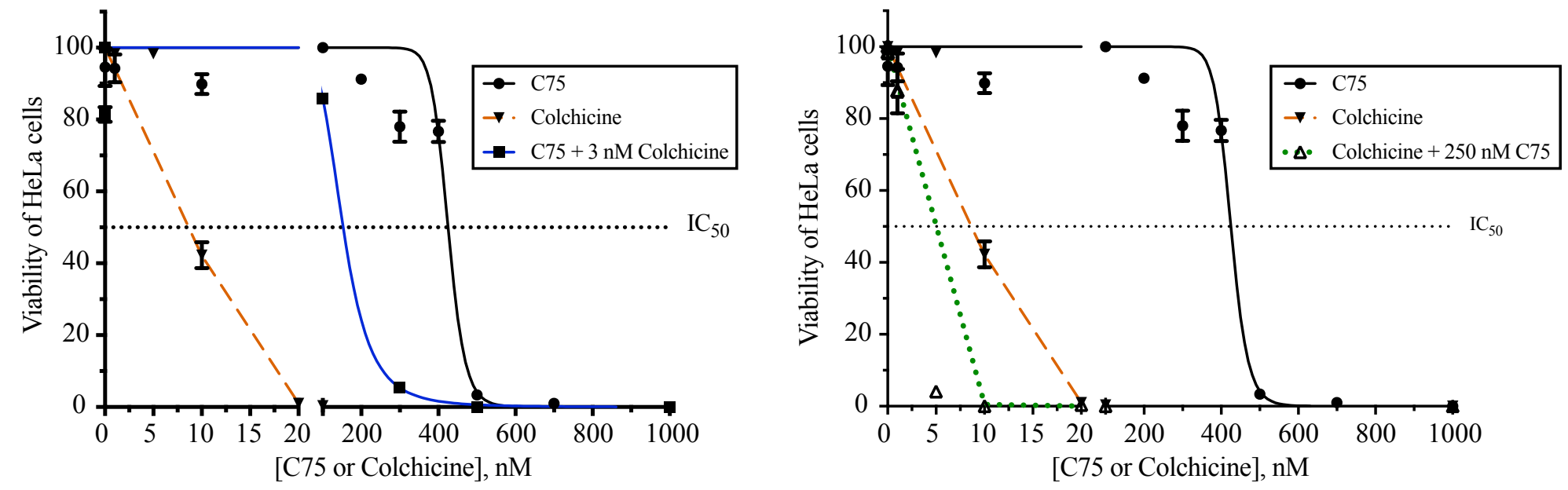

B

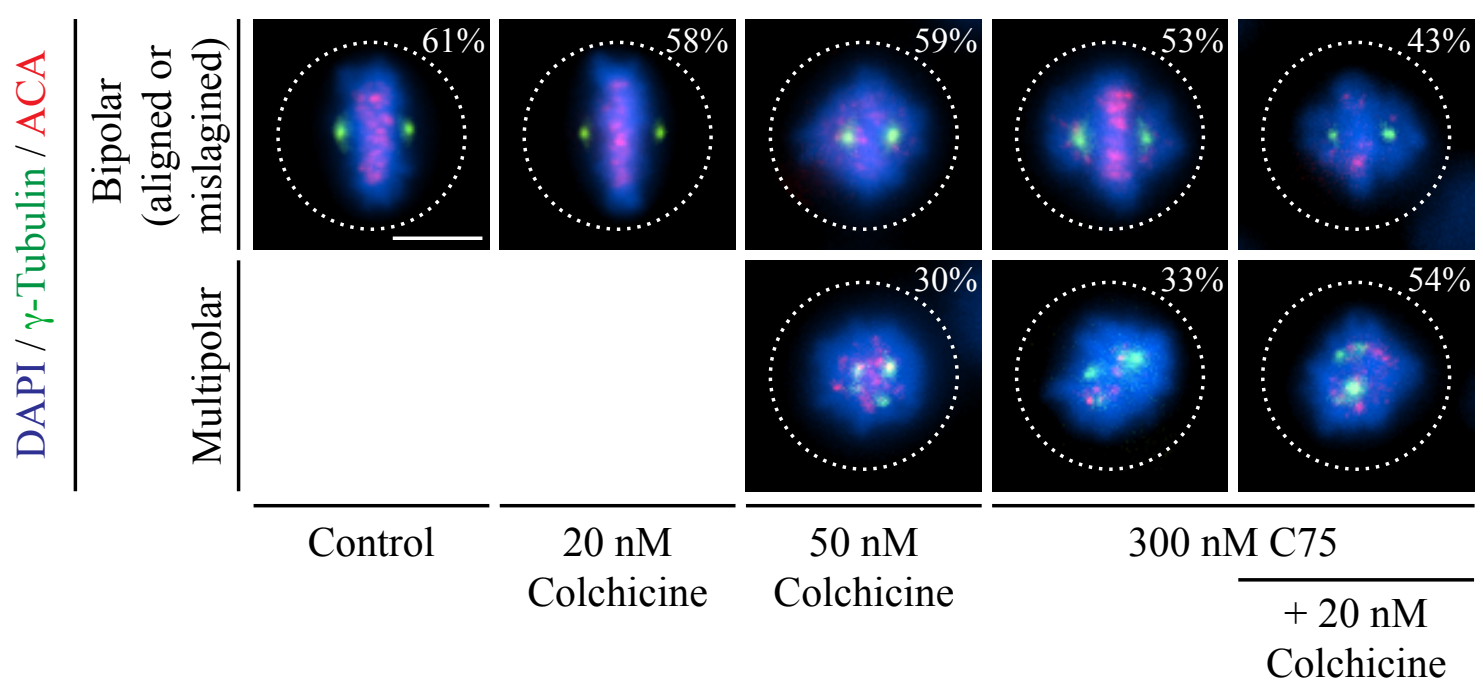

C

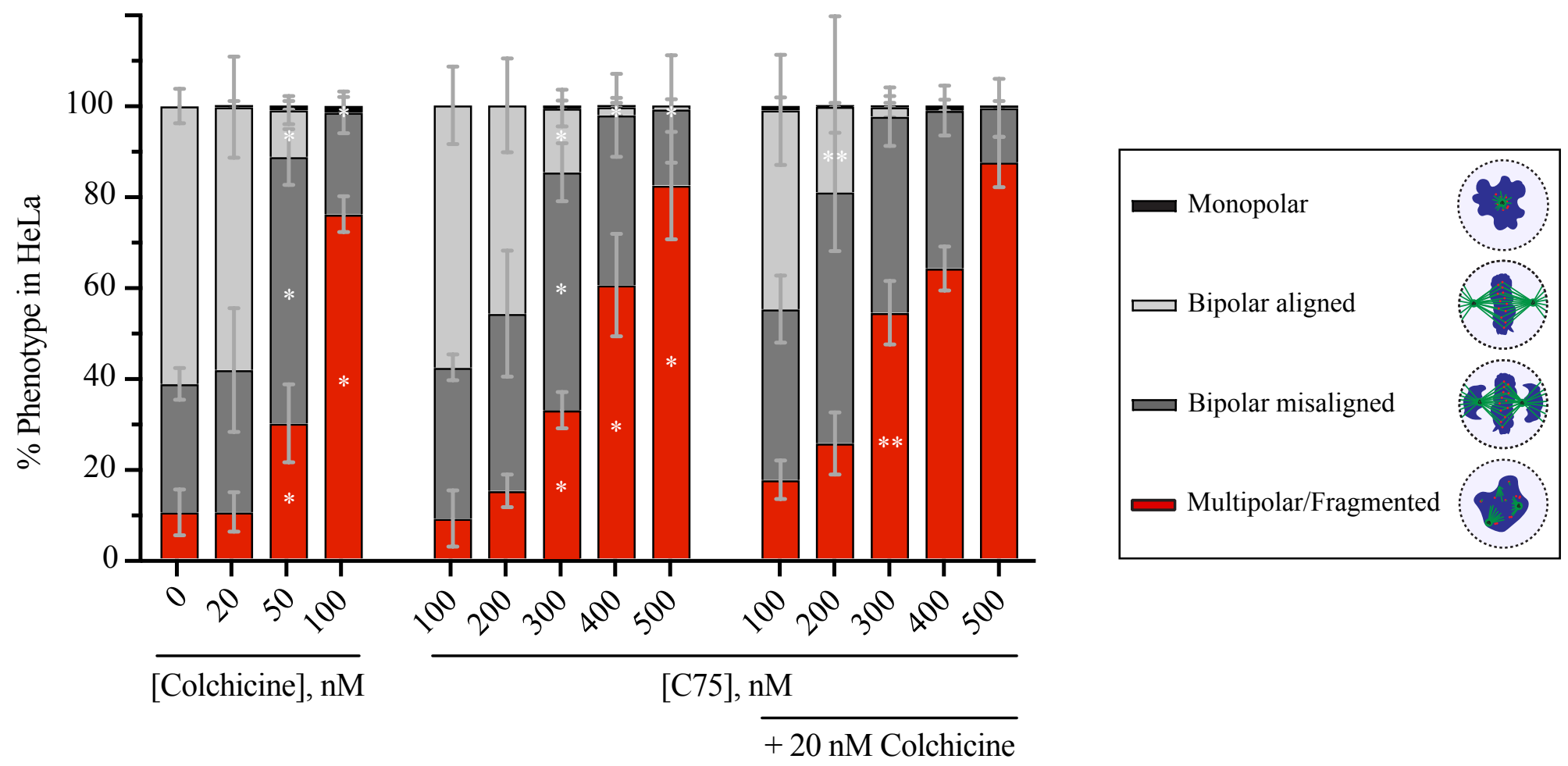


bioRxiv preprint doi: https://doi.org/10.1101/2020.08.14.251058; this version posted August 14, 2020. The copyright holder for this preprint (which was not certified by peer review) is the author/funder, who has granted bioRxiv a license to display the preprint in perpetuity. It is made A
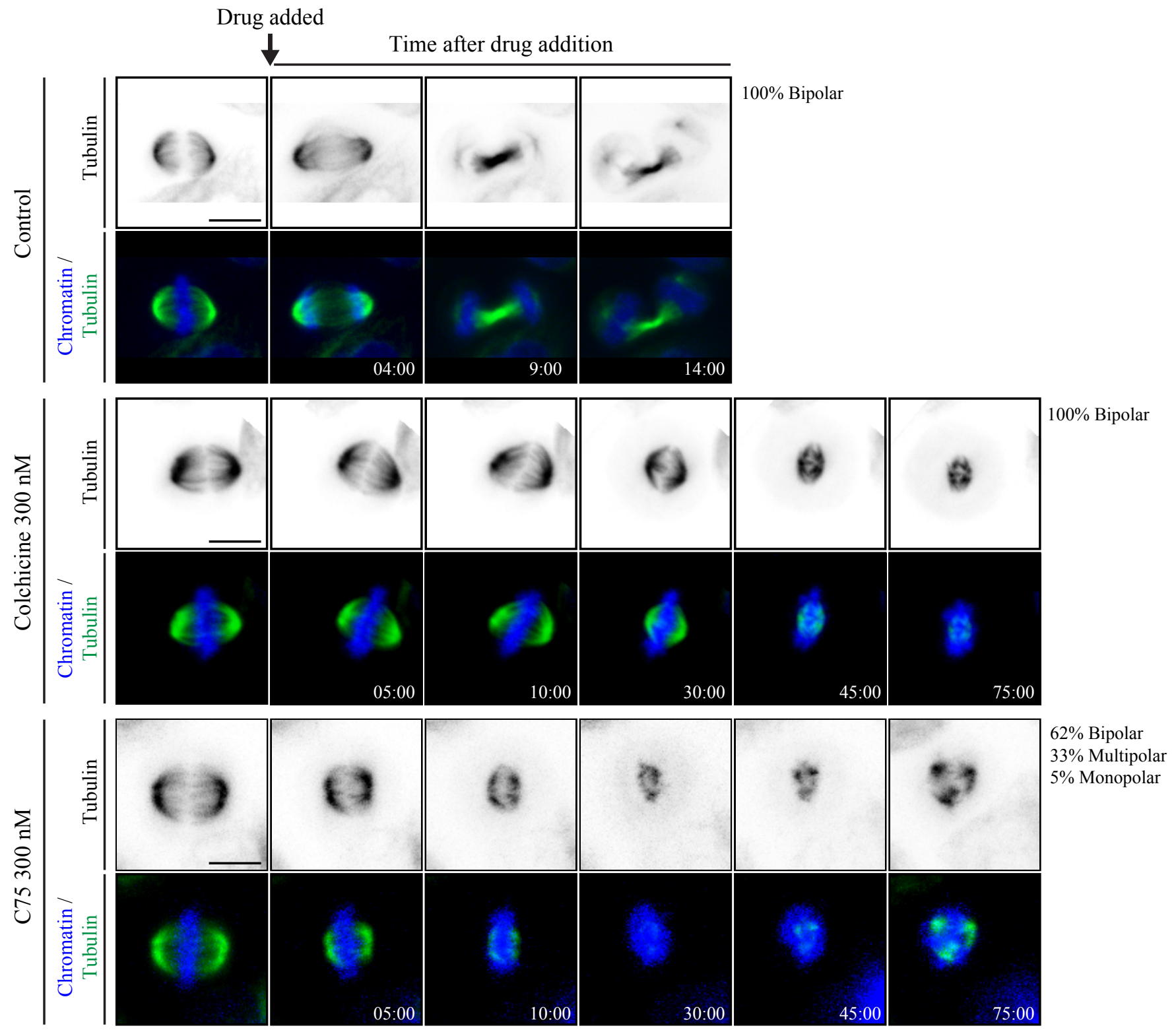

B
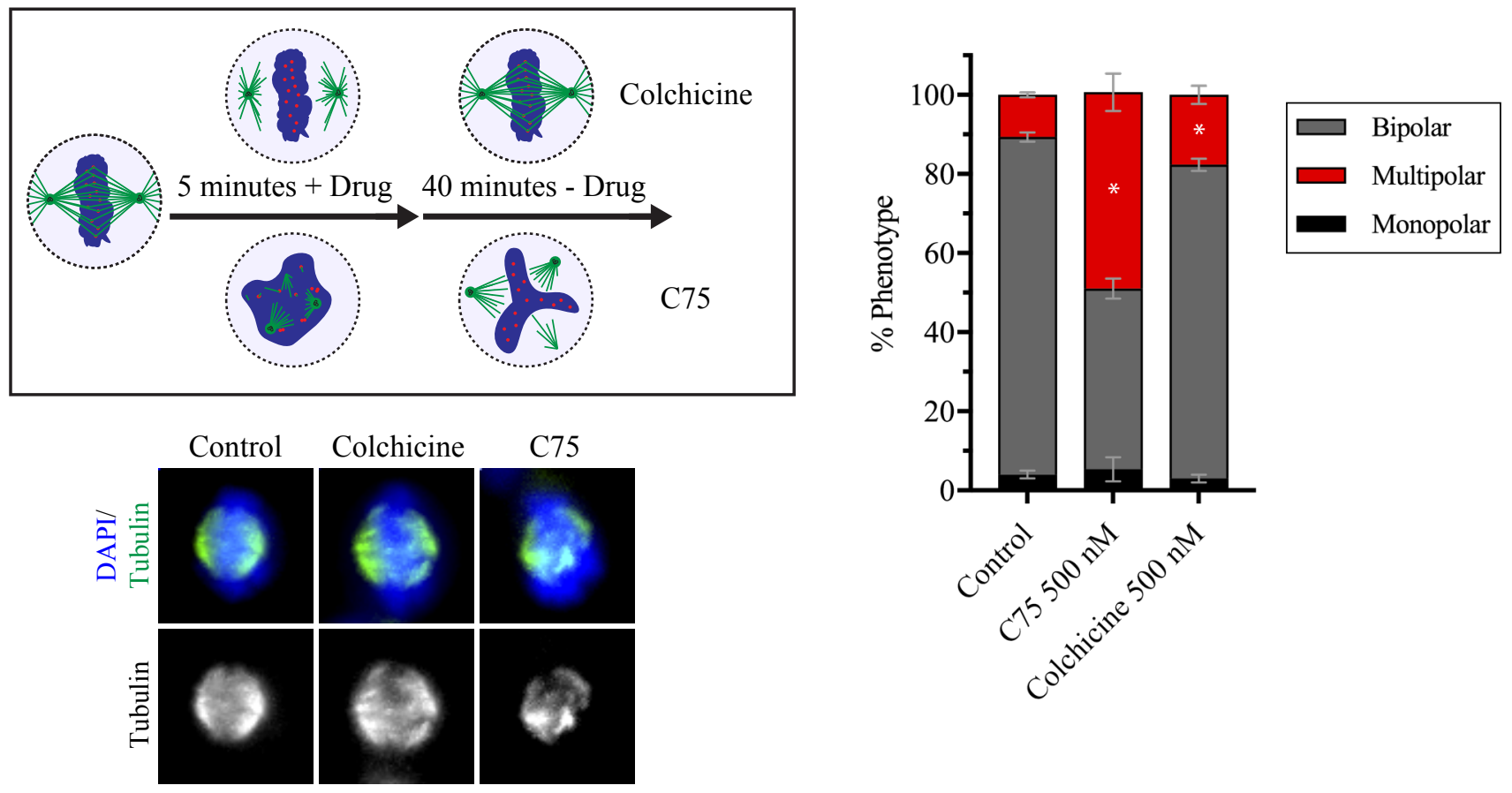
bioRxiv preprint doi: https://doi.org/10.1101/2020.08.14.251058; this version posted August 14, 2020. The copyright holder for this preprint (which was not certified by peer review) is the author/funder, who has granted bioRxiv a license to display the preprint in perpetuity. It is made

$\mathbf{A}$ available under aCC-BY-NC 4.0 International license.

o.

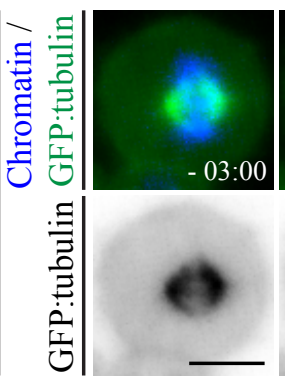

$\sum$
0
0
0
0
0
0
0
0
0
0

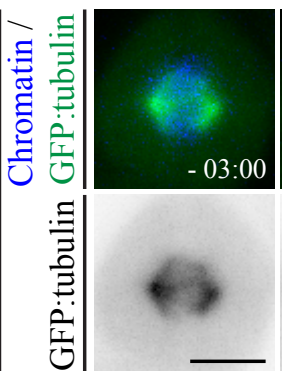

$\sum^{2}$
8
0
$i$
0
0

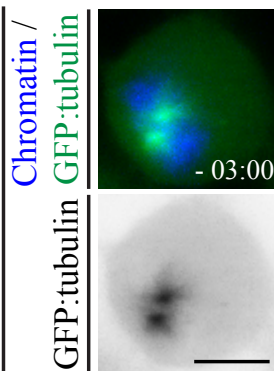

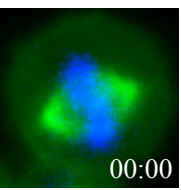
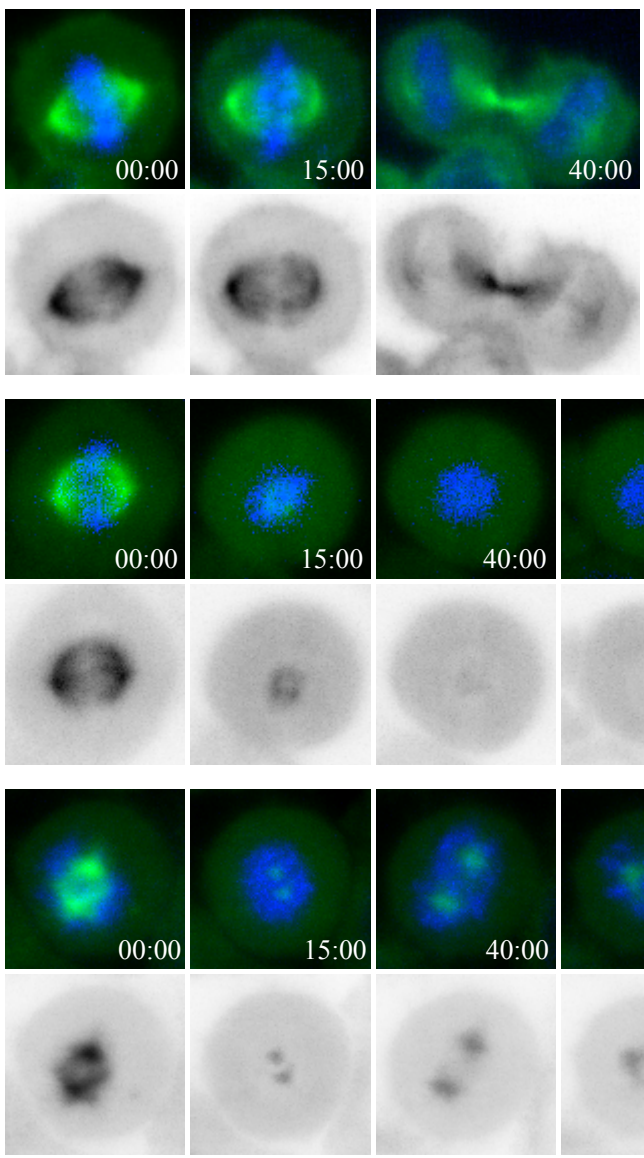

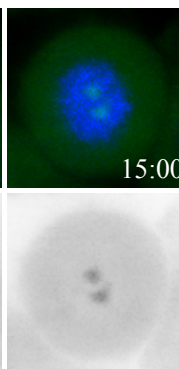

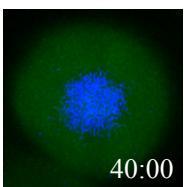

B

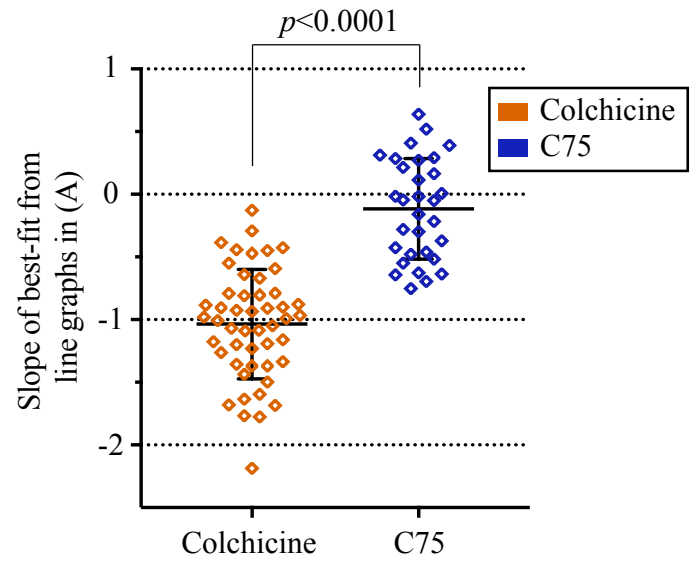

C

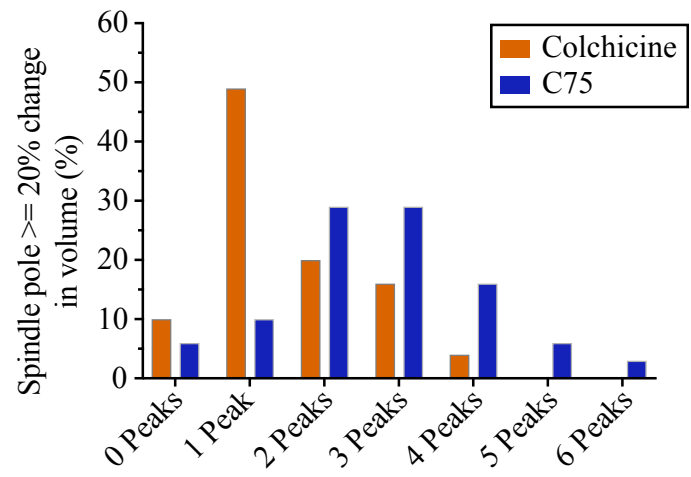

D
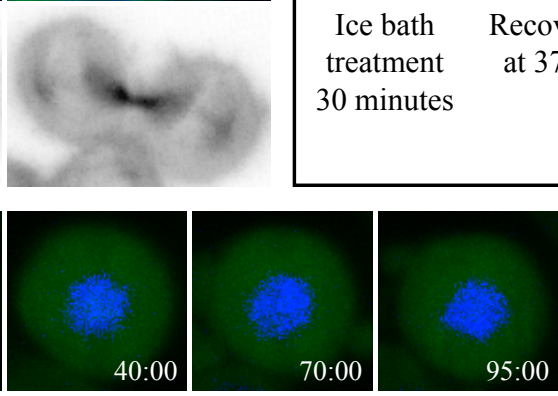

Drug Added 15 minutes 25 minutes 40 minutes $\mathrm{T}=0$ minutes

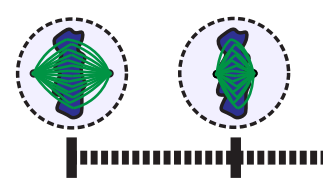

Ice bath Recovery treatment at $37^{\circ} \mathrm{C}$ 30 minutes
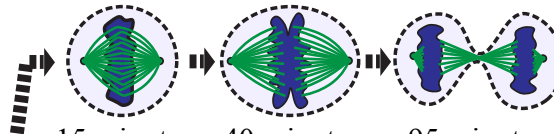

No Drug

15 minutes 40 minutes 95 minutes

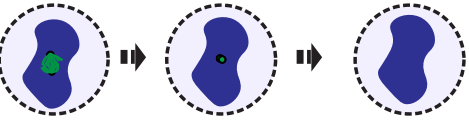

$300 \mathrm{nM}$ Colchicine
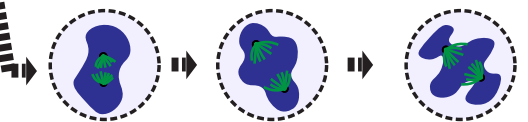

$300 \mathrm{nM}$ C75
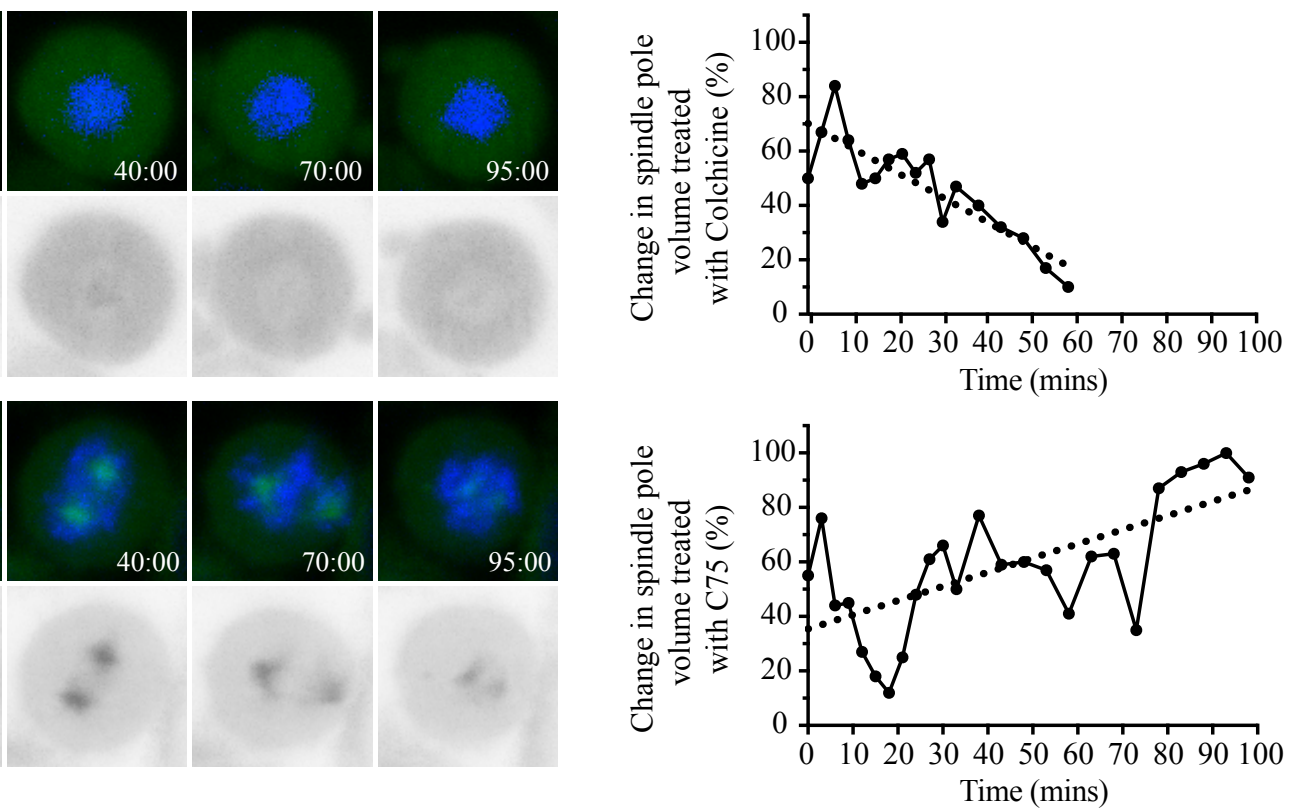

Time (mins) $0 \quad 3 \quad 6 \quad 9121518212427303338434853586368737883889398$

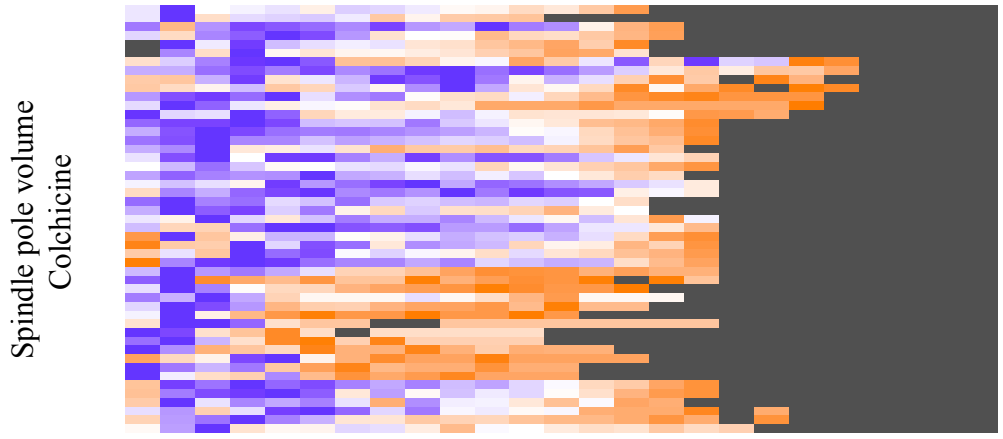

Time (mins) $0 \quad 3 \quad 6 \quad 9121518212427303338434853586368737883889398$
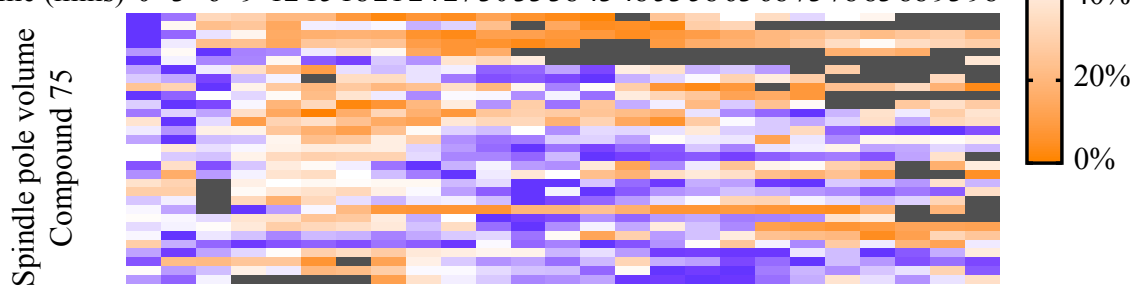


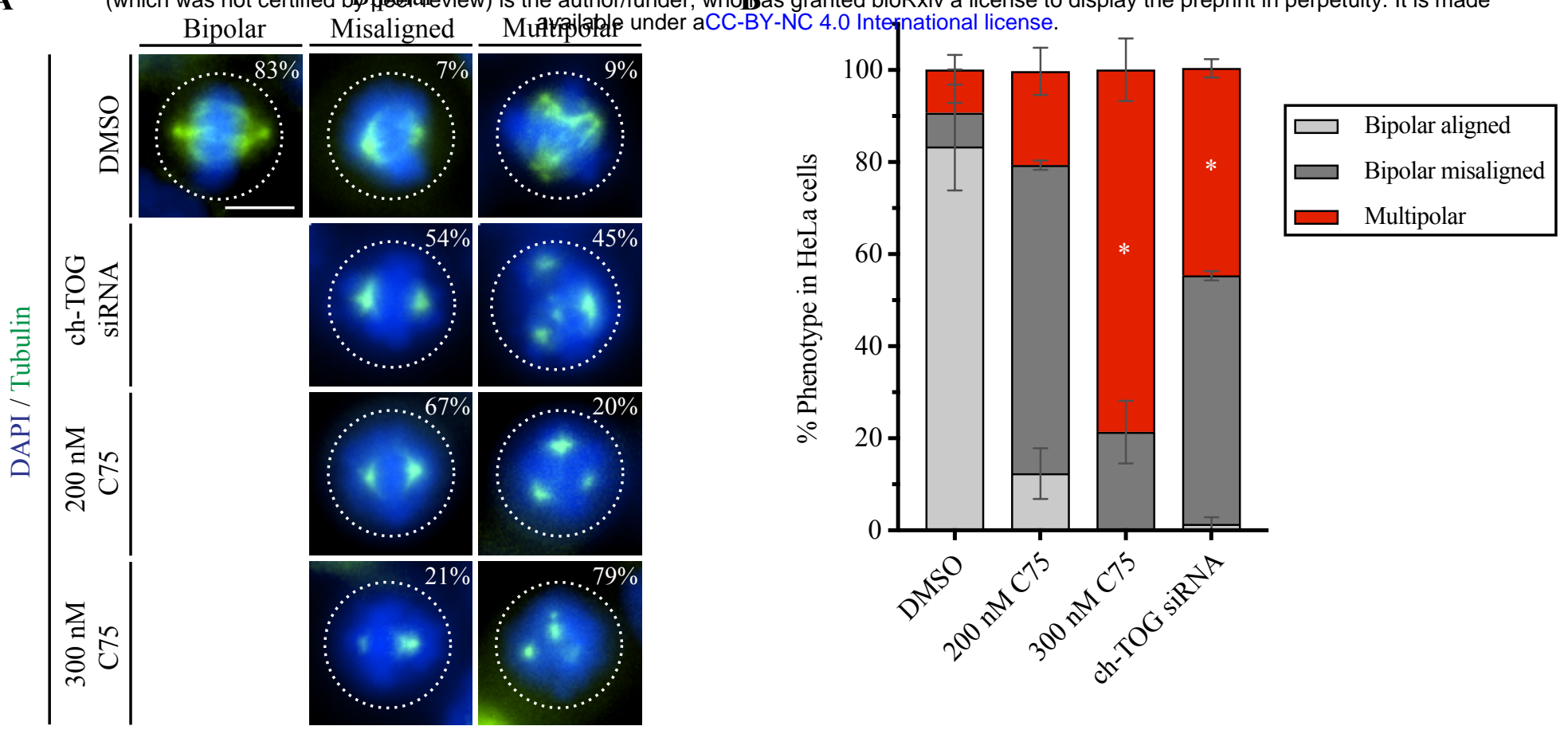

C
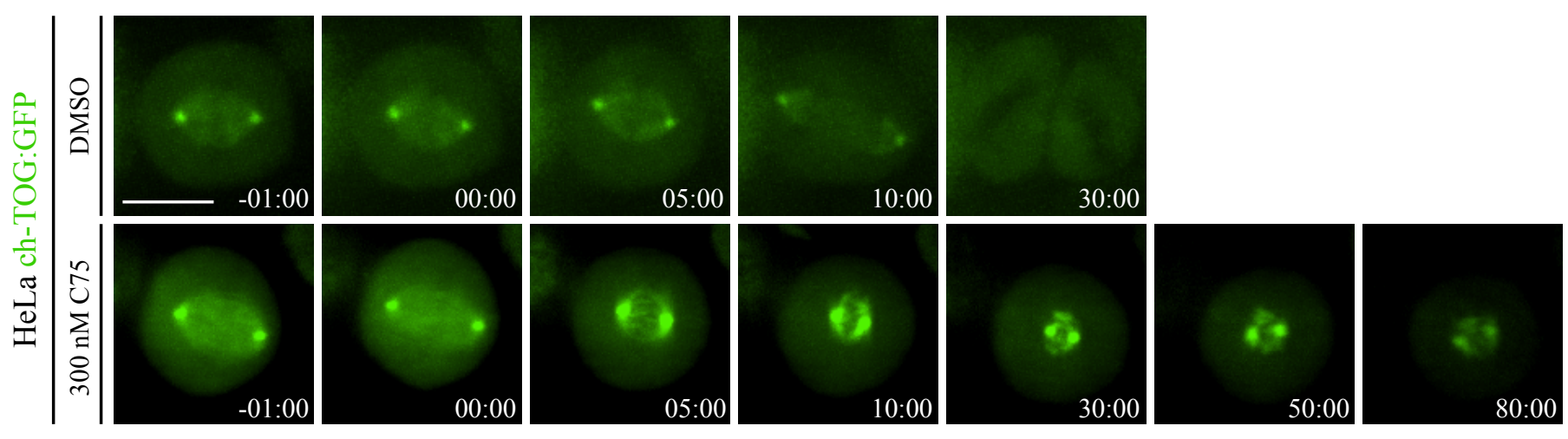

D

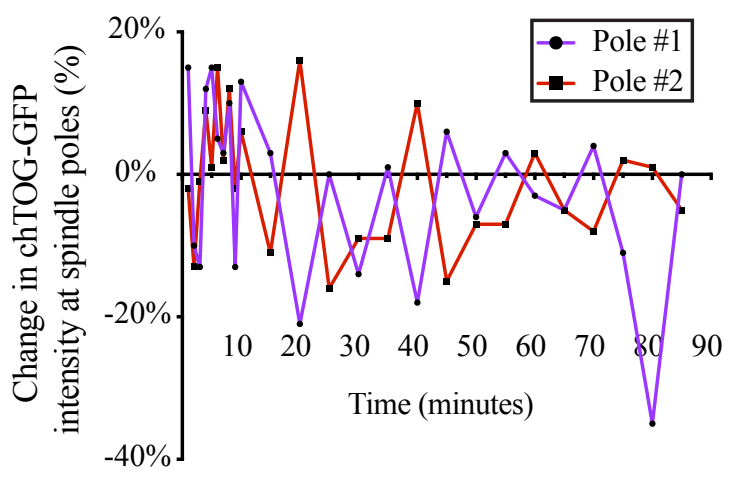

E

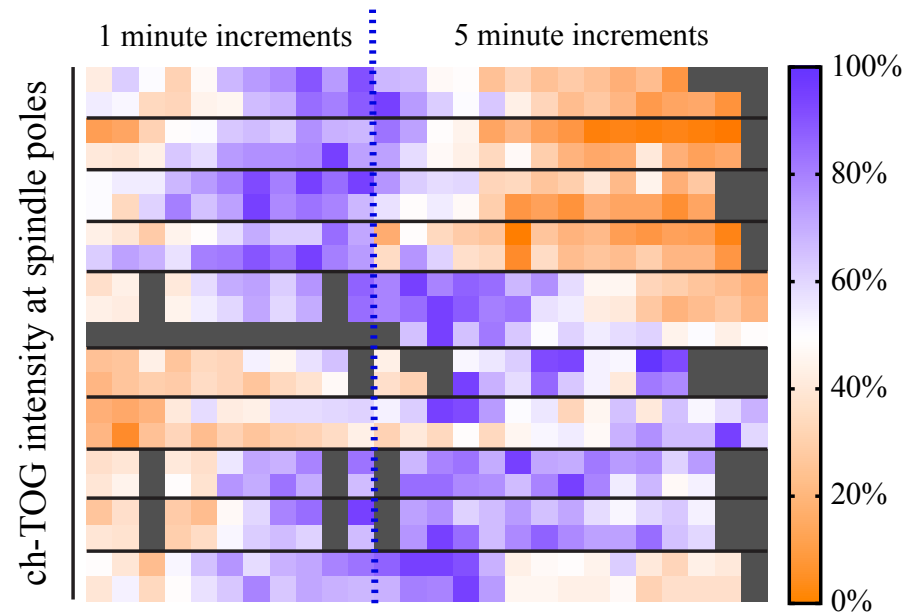

F

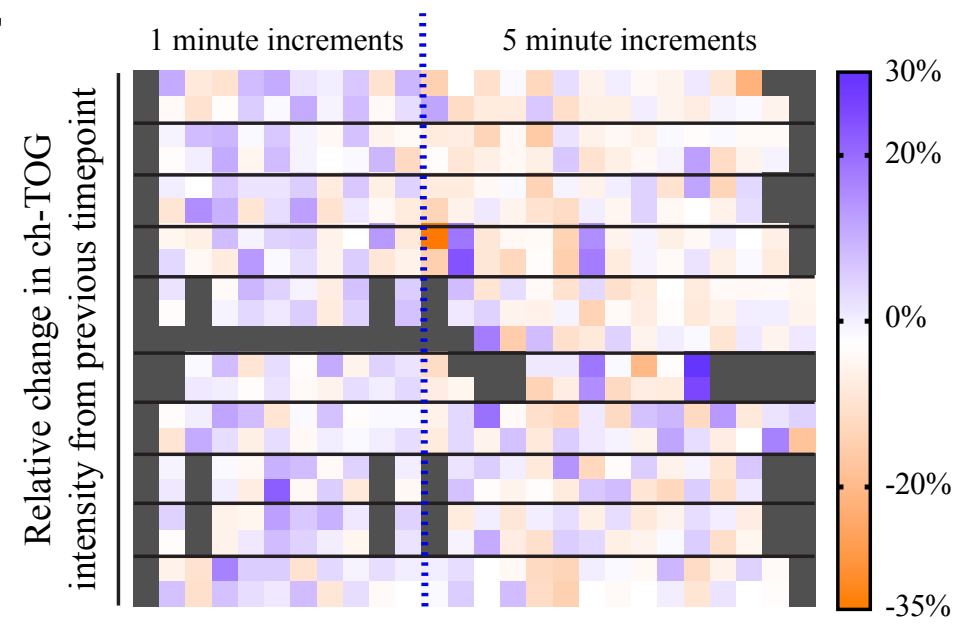

